$$
\begin{gathered}
\text { UNIVERSIDADE DE SÃO PAULO } \\
\text { FACULDADE DE MEDICINA DE RIBEIRÃO PRETO } \\
\text { PROGRAMA DE PÓS-GRADUAÇÃO EM FARMACOLOGIA }
\end{gathered}
$$

EFEITOS DO CANABIDIOL NO COMPORTAMENTO AGRESSIVO INDUZIDO POR ISOLAMENTO SOCIAL EM CAMUNDONGOS

ALICE HARTMANN DOS SANTOS

Ribeirão Preto

2016 


$$
\begin{gathered}
\text { UNIVERSIDADE DE SÃO PAULO } \\
\text { FACULDADE DE MEDICINA DE RIBEIRÃO PRETO } \\
\text { PROGRAMA DE PÓS-GRADUAÇÃO EM FARMACOLOGIA }
\end{gathered}
$$

\section{EFEITOS DO CANABIDIOL NO COMPORTAMENTO AGRESSIVO INDUZIDO POR ISOLAMENTO SOCIAL EM CAMUNDONGOS}

ALICE HARTMANN DOS SANTOS

Dissertação apresentada à Faculdade de Medicina de Ribeirão Preto da Universidade de São Paulo para obtenção do título de Mestre em Ciências.

Área de concentração: Farmacologia.

Orientador: Dr. Francisco Silveira Guimarães.

Ribeirão Preto

2016 
AUTORIZO A REPRODUÇÃO E DIVULGAÇÃO TOTAL OU PARCIAL DESTE

TRABALHO, POR QUALQUER MEIO CONVENCIONAL OU ELETRÔNICO, PARA

FINS DE ESTUDO E PESQUISA, DESDE QUE CITADA A FONTE.

\section{FICHA CATALOGRÁFICA}

Preparada pela Biblioteca Central do Campus Administrativo de Ribeirão Preto/USP

Hartmann, Alice.

Efeitos do canabidiol no comportamento agressivo induzido por isolamento social em camundongos / Alice Hartmann; orientador: Francisco Silveira Guimarães.

$74 \mathrm{p}$.

Dissertação (Mestrado em Ciências - Área de Concentração: Farmacologia) Faculdade de Medicina de Ribeirão Preto, Universidade de São Paulo, Ribeirão Preto, SP, 2016.

1. Canabidiol. 2. Agressividade. 3. Residente-Intruso. 4. Receptor CB1. 5. Receptor 5-HT1A. 
Nome: HARTMANN, Alice.

Título: Efeitos do canabidiol no comportamento agressivo induzido por isolamento social em camundongos.

Dissertação apresentada à Faculdade de Medicina de Ribeirão Preto da Universidade de São Paulo para obtenção do título de Mestre em Ciências.

Aprovado em:

Banca Examinadora

Prof. Dr.: Rosa Maria Martins de Almeida

Instituição: Universidade Federal do Rio Grande do Sul (UFRGS).

Julgamento:

Assinatura:

Prof. Dr.: Antonio Waldo Zuardi

Instituição: Faculdade de Medicina de Ribeirão Preto - USP (FMRP-USP)

Julgamento:

Assinatura:

Prof. Dr.: Francisco Silveira Guimarães

Instituição: Faculdade de Medicina de Ribeirão Preto - USP (FMRP-USP) Julgamento:

Assinatura: 
Aos meus pais, irmãs, sobrinhos e namorado por serem a minha maior fonte de amor, incentivo, esperança e força. 


\section{AGRADECIMENTOS}

À Deus pelo dom da vida. Obrigada por me guiar e proteger em todas as situações e escolhas feitas durante a minha existência, bem como por todas as oportunidades e dificuldades que me foram impostas.

Aos meus amáveis pais, Ivone e Abgair, por serem os meus maiores exemplos. Obrigada por entenderem a minha ausência e, ainda assim, serem os meus maiores incentivadores. Obrigada por todas as oportunidades, sacrifícios, amor, carinho, educação, compreensão e apoio durante esses 25 anos de existência. Tudo em minha vida é para e por vocês.

Às minhas eternas 'irmães', Christina e Ana Raquel, por fazerem de mim a sua boneca. Obrigada por todas as brincadeiras, arrumações pré-apresentações infantis, tarefas escolares e mimos - enfim, agradeço por todo amor, paciência e carinho a mim dispensados até hoje. Obrigada por torcerem e se orgulharem de mim.

Aos meus eternos bebês - Carolina, Vitor, Fernando e Francisco - por me permitirem enxergar um mundo melhor e me darem esperança. Obrigada pelos ingênuos ensinamentos e carinhos.

Ao meu namorado, Gustavo, pelo inestimável e incansável companheirismo e apoio durante a graduação e a pós-graduação. Obrigada por ser a minha família quando estou longe de casa. Obrigada por ser a minha fonte de amor, carinho, equilíbrio e paz nos momentos de incerteza e fúria. Obrigada por compartilhar comigo o seu conhecimento e me incentivar/inspirar a ser melhor a cada dia. Obrigada por me compreender, me dar a oportunidade de conviver diariamente contigo, por seguirmos lado a lado nessa difícil jornada. Obrigada pelo apoio incondicional independentemente da situação. Obrigada, simplesmente, por ser como você é.

Ao mestre, Francisco Silveira Guimarães, pelo aceite em seu laboratório, oportunidades, confiança, ensinamentos e paciência. Obrigada pelos momentos de descontração, por me tranquilizar em épocas conturbadas, me fazer enxergar o lado positivo dos muitos experimentos "em vão" e, até mesmo, por fazer de mim um pouco menos "naive" como o Sr. mesmo diz. Obrigada pela constante preocupação com nosso bem estar e em fazer "nos sentirmos em casa".

À minha veterana científica, Sabrina, a minha eterna gratidão. Obrigada pelas palavras amigas, por confiar em mim e por sempre me fazer enxergar a luz no fim do túnel. Obrigada pelas risadas, pela presença virtual quando a física não foi possível, por todo auxílio científico e por compartilhar o seu conhecimento comigo. Obrigada por, juntamente com o 
Felipe, terem confiado esse projeto a mim. O que é seu está maravilhosamente bem guardado!

Ao nosso menino prodígio, Felipe, por fazer os momentos desesperadores virarem situações engraçadas diante das suas risadas e comentários. Obrigada pelos momentos de descontração e por compartilhar o seu conhecimento e experiências científicas. Obrigada pelos desafios intelectuais que me fazia sempre que chegava para perguntar qual o próximo passo a seguir; e por sempre me auxiliar e ensinar, mesmo que virtualmente. Obrigada por, juntamente com a Sa, terem confiado esse projeto a mim.

Às minhas amáveis companheiras de laboratório - Andreza, Carla, Manoela, Naielly e Nicole - por todo companheirismo e amizade. Obrigada pelas discussões científicas, idas a cantina, pelas risadas e momentos de descontração. Obrigada por toda a preocupação, por me alegrarem dentro e fora do laboratório, por fazerem o convívio diário ser prazeroso e por ampararmos umas às outras quando necessário. Agradeço, especialmente, a Andrezinha por ter sido a minha primeira forma de contato com o Chico, por toda receptividade quando cheguei ao lab pela primeira vez, pelo constante apoio na realização dos experimentos e discussões a respeito dos resultados do presente trabalho - você é muito especial!

Ao Prof. Leonardo pela amizade, carinho, ensinamentos e dedicação. Obrigada por ter aberto as portas e me acolhido tão bem em seu laboratório, por me auxiliar diante dos momentos de incerteza, por confiar no meu trabalho e me apoiar. Obrigada pelas risadas, momentos de descontração, por toda atenção e apoio que sempre me deu.

Ao Prof. Morgan pela receptividade, preocupação e disposição. Obrigada por permitir, juntamente com seus alunos e com a Vá, que me sinta confortável e acolhida em seu laboratório.

À Prof. Alline pela disposição em auxiliar, pelas sugestões e discussões científicas. Obrigada pela prestatividade e atenção dispensada a mim sempre que precisei.

Aos meus amáveis colegas dos laboratórios de Neurofarmacologia e Controle Central da Pressão Arterial - Leandro, Dani, May, Davi, Luciana, Gabi, Sara, Teo, Jéssica, Anna Bárbara, Ana Terzian, Aline, Cris e América - por toda amizade, companheirismo, apoio e paciência. Obrigada por me acolherem e por permitirem que eu trabalhasse e convivesse com vocês. Obrigada, principalmente, por todas as risadas e descontrações. Tedexquinha, agradeço a sua disposição em sempre me auxiliar e ensinar, admiro a sua pró-atividade e empolgação com o que faz, sinto muito orgulho em ter tido a oportunidade de trabalhar contigo e de ter a sua amizade! Lezinho, obrigada simplesmente por ser você, por ser a minha fonte de risadas e descontração, por sempre estar disposto a discutir e a ensinar quando precisei! 
Aos "meus" meninos e meninas da casa amarela - Pandinha, Kalil, Mikhael, Dênis, Nerry, Alynne - por me acolherem antes mesmo de a república ser a casa amarela. Obrigada pelas festas, risadas, amizade, convívio, companheirismo, carinho e apoio. Obrigada por me incentivarem a vir para Ribeirão e pelos momentos de descontração nos corredores.

Aos meus amigos e companheiros dessa intensa e desgastante jornada de pós-graduação Nicole, Andreza, Carla, Leandro, Cassiano, Dani, May, Ana Terzian, Teophanes, Aline e Douglas - obrigada por permitirem o convívio diário agradável, por serem a minha válvula de escape quando necessário e, principalmente, por terem feito meus dias mais alegres. Pretinha, agradeço especialmente a você por estar comigo desde o início, por termos entrado juntas nessa etapa, enfrentado as mesmas angústias de um ano de mestrado sem resultados, pelo seu companheirismo, inocência e amizade! A caminhada sem vocês, seria impossível.

Aos demais Professores e colegas pós-graduandos do Depto. de Farmacologia pela cordialidade e disposição em me auxiliar quando necessário, bem como pelas conversas descontraídas nos corredores.

Aos amigos do Depto. de Imunologia que, desde sempre, me acolheram maravilhosamente bem. Obrigada pelos momentos de descontração, risadas e festas.

Ao apoio técnico de Laura, José Carlos, Eleni, Inês e Marcos. Laura, muito obrigada pela eficiência e disposição em sempre me auxiliar, pelas risadas e pelo apoio. Zé, meu adorado, orgulho em ter te conhecido, em ter tido a oportunidade de conviver e trabalhar contigo muito obrigada por tudo. Inês, Marquinhos e Eleni, obrigada pela agradável convivência, disposição e auxílio diário no laboratório.

Ao apoio técnico de Eliana, Orlando e Marcos no cuidado com os animais do biotério.

Aos secretários do Depto. de Farmacologia - Ramón, Soninha e Fátima - pela competência, disponibilidade, carinho e atenção com que sempre nos recebem e resolvem nossos problemas. Ramón, muito obrigada pelas conversas e amizade dentro e fora da USP. Soninha e Fátima, muito obrigada por todo carinho, paciência e auxílio no nosso dia-a-dia e, principalmente, em momentos conturbados como processos seletivos, defesa e cursos de inverno.

Aos membros da banca, Dr. Antonio W. Zuardi e Dra. Rosa Maria de Almeida pela disponibilidade, atenção, auxílio e colaboração na finalização deste trabalho.

Ao Conselho Nacional de Desenvolvimento Científico e Tecnológico (Cnpq) pelo apoio financeiro.

A todos aqueles que contribuíram direta ou indiretamente para a realização deste trabalho. 
"Se você encontrar um caminho sem obstáculos, ele provavelmente não leva a lugar nenhum." 
$\underline{\text { Resumo }}$ 


\section{RESUMO}

HARTMANN, A. Efeitos do canabidiol no comportamento agressivo induzido por isolamento social em camundongos. 2016. 74 p. Dissertação (Mestrado). Faculdade de Medicina de Ribeirão Preto - Universidade de São Paulo, 2016.

O Canabidiol (CBD), principal composto não-psicotomimético da Cannabis sativa, possui diversas propriedades farmacológicas, incluindo a indução de efeitos tipoantidepressivos e ansiolíticos em roedores após administração sistêmica. O isolamento social aumenta comportamentos agressivos em camundongos, condição denominada agressão induzida pelo isolamento social ou agressão territorial. Drogas ansiolíticas e antidepressivas podem atenuar comportamentos agressivos. Desse modo, o objetivo do presente trabalho foi avaliar se o CBD atenuaria comportamentos agressivos induzidos pelo isolamento social em camundongos. Camundongos Suíços machos (7-8 semanas de idade no dia do isolamento, 30-40 g no dia do teste) foram mantidos isolados (camundongos residentes) para indução dos comportamentos agressivos. Paralelamente, camundongos co-específicos (camundongos intrusos) foram mantidos agrupados (oito por caixa). Neste modelo, um camundongo intruso da mesma linhagem, sexo e idade foi colocado na caixa moradia do residente. As interações entre os camundongos residente e intruso foram gravadas por 20 min e a latência para a primeira mordida contra o intruso, 0 número de ataques e o tempo total de ataques foram analisados por um observador cego aos grupos experimentais. Após 10 dias de isolamento social, foi testado se a administração aguda (i.p.) de $\operatorname{CBD}(5,15,30$ ou $60 \mathrm{mg} / \mathrm{kg}$ ), $30 \mathrm{~min}$ antes do teste, atenuaria comportamentos agressivos dos camundongos residentes contra os intrusos. Para avaliar a participação de receptores 5-HT1A e CB1 nos efeitos do $\mathrm{CBD}$, grupos independentes de animais receberam 1 injeção prévia de WAY 100635 (antagonista dos receptores 5-HT1A, 0,3 mg/kg) ou AM251 (antagonista dos receptores CB1, $1 \mathrm{mg} / \mathrm{kg}), 30 \mathrm{~min}$ antes do CBD (15 mg/kg). Para controlar possíveis efeitos motores da droga, grupos independentes de animais tratados com doses efetivas de CBD ou não efetivas de WAY100635 ou AM251 foram submetidos ao actímetro para avaliação da atividade locomotora total. O CBD $(15 \mathrm{mg} / \mathrm{kg})$ aumentou a latência para o residente atacar o intruso e este efeito foi atenuado tanto pela

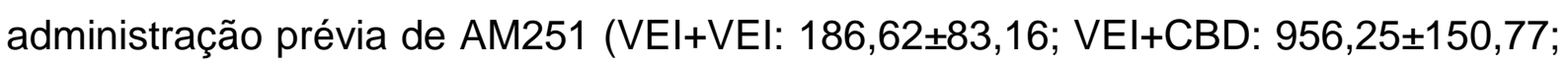
AM+VEI: $271,71 \pm 156,18 ; A M+C B D: 395,86 \pm 208,24 ; p=0,030)$ quanto WAY100635 
(VEI+VEI: 116,33 $\pm 29,38 ; \quad V E I+C B D: \quad 860,87 \pm 177,36 ; W A Y+V E I: \quad 305,12 \pm 159,16$; WAY+CBD: 302,57 $\pm 154,68 ; p=0,011)$. Além disso, o CBD reduziu o número de ataques em todas as doses testadas (VEI: $23,00 \pm 3,66$; CBD 5: 12,25 $\pm 2,43$; CBD 15:

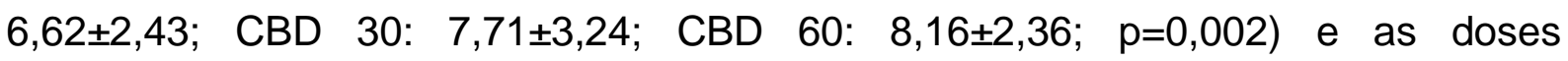
intermediárias (15 e $30 \mathrm{mg} / \mathrm{kg}$ ) foram capazes de diminuir o tempo total de ataques (VEI: $114,37 \pm 22,65 ;$ CBD 5: $80,87 \pm 23,83 ; \operatorname{CBD} 15: 40,00 \pm 14,58 ; \operatorname{CBD} 30$ : 25,86 $\pm 12,88$; CBD 60: $54,67 \pm 9,68 ; p=0,018$ ), ambos os efeitos sendo atenuados

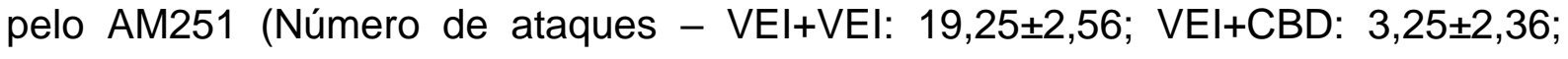
$A M+V E I: 22,86 \pm 4,97 ; A M+C B D: 14,14 \pm 4,10 ; p=0,028$; Tempo total de ataques VEI+VEI: 66,62 $\pm 9,19$; VEI+CBD: 11,75 $\pm 9,56 ; A M+V E I: ~ 118,86 \pm 31,00 ; A M+C B D$ :

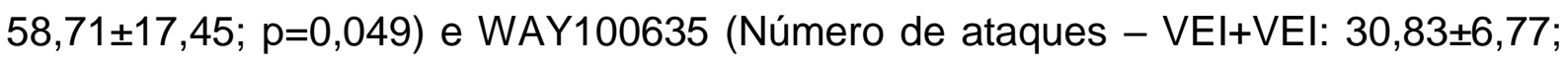
VEI+CBD: 7,87 $\pm 4,68 ; W A Y+V E I: 22,50 \pm 5,06 ; W A Y+C B D: 23,57 \pm 6,74 ; p=0,059$;

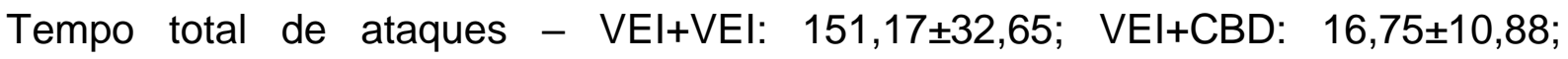

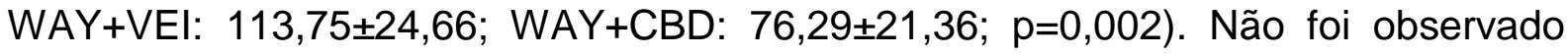
efeito motor do CBD em nenhuma das doses testadas, bem como do WAY100635 e AM251. Esses resultados evidenciam que o CBD atenua comportamentos agressivos em camundongos e nos permitem sugerir um mecanismo misto, visto que há o envolvimento de receptores $\mathrm{CB} 1$ e 5-HT1A. Desse modo, este fitocanabinoide poderia ser uma alternativa terapêutica para tratar comportamentos agressivos associados a transtornos psiquiátricos.

Palavras-chave: Canabidiol, Agressividade, Residente-Intruso, Receptor CB1, Receptor 5-HT1A. 
Abstract 


\section{ABSTRACT}

HARTMANN, A. Cannabidiol effects on agressive-like behaviors induced by social isolation in mice. 2016. 74 p. Master's Degree Work. Ribeirão Preto Medical School - University of São Paulo, 2016.

Cannabidiol (CBD), a major non-psychotomimetic compound from Cannabis sativa plant, induces anxiolytic- and antidepressant-like effects in rodents after systemic administration. Long-term individual housing increases aggressive behavior in mice, a condition named isolation-induced aggression or territorial aggression, which can be attenuated by anxiolytic and antidepressant drugs. Thus, the aim of the present study was to verify whether CBD would attenuate the aggressive behavior induced by social isolation. Male Swiss mice (7-8 weeks of age on the isolation day, 30-40 $\mathrm{g}$ on the test day) were individually housed (resident mice) to induce aggressive behavior, while conspecific mice (intruder mice) were grouped housed (eight per cage). In this model, an intruder mouse of the same strain, sex and age is placed in the resident home cage. The resident-intruder interactions were videotaped for 20 min and the latency to the first bite against the intruder, the number of attacks and the total duration of aggressive encounters were recorded and later analyzed by an observer blind to the treatment groups. After 10 days of social isolation, we tested if acute intraperitoneal CBD administration (5, 15, 30 and $60 \mathrm{mg} / \mathrm{kg}$ ) to the resident mice 30 min prior to the test would attenuate aggressive-like behavior towards the intruder animal. To evaluate the involvement of $5-\mathrm{HT} 1 \mathrm{~A}$ and $\mathrm{CB} 1$ receptors in the CBD effects, independent groups of animals were injected with WAY100635 (0.3 $\mathrm{mg} / \mathrm{kg}$ ) or AM251(1 mg/kg) $30 \mathrm{~min}$ prior to CBD (15 mg/kg). To control possible motor effects, independent animals treated with effective doses of CBD or ineffective doses of WAY100635 or AM251 were submitted to the actimeter to evaluate the total locomotor activity. CBD (15 mg/kg) increased latency to attack the intruder and this effect was attenuated by the prior administration of AM251 (VEI+VEI: 186.62 \pm 83.16 ; VEI+CBD: 956.25 $\pm 150.77 ; \quad A M+V E I: 271.71 \pm 156.18 ; A M+C B D: 395.86 \pm 208.24$;

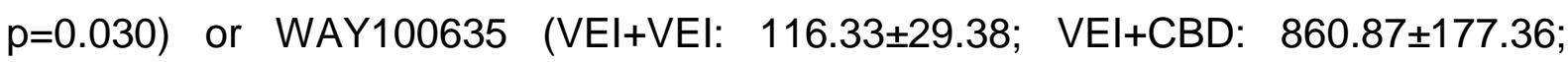
WAY+VEI: 305.12 \pm 159.16 ; WAY+CBD: 302.57 $\pm 154.68 ; p=0.011)$. Moreover, CBD reduced the number of attacks in all tested doses (VEI: 23.00 \pm 3.66 ; CBD 5:

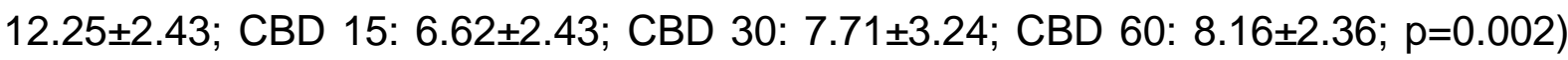
as well as the duration of aggressive behavior encounters in the intermediary doses 
(15 and $30 \mathrm{mg} / \mathrm{kg}$; VEl: $114.37 \pm 22.65$; CBD 5: 80.87 \pm 23.83 ; CBD 15: $40.00 \pm 14.58$; CBD 30: 25.86 $\pm 12.88 ; C B D$ 60: $54.67 \pm 9.68 ; p=0.018$ ), both effects were attenuated by AM251 (Number of attacks - VEI+VEI: 19.25 \pm 2.56 ; VEI+CBD: $3.25 \pm 2.36$; $A M+V E I: 22.86 \pm 4.97 ; A M+C B D: 14.14 \pm 4.10 ; p=0.028$; Total time of attacks VEI+VEI: 66.62 $\pm 9.19 ; \mathrm{VEI}+\mathrm{CBD}: 11.75 \pm 9.56 ; \mathrm{AM}+\mathrm{VEI}: 118.86 \pm 31.00 ; \mathrm{AM}+\mathrm{CBD}$ : 58.71 $\pm 17.45 ; p=0.049$ ) and WAY100635 (Number of attacks - VEI+VEI: 30.83 \pm 6.77 ; VEI+CBD: 7.87 $\pm 4.68 ; W A Y+V E I: 22.50 \pm 5.06 ; W A Y+C B D: 23.57 \pm 6.74 ; p=0.059$; Total time of attacks $-\mathrm{VEI}+\mathrm{VEI}: 151.17 \pm 32.65$; VEI+CBD: $16.75 \pm 10.88$; WAY+VEI: 113.75 \pm 24.66 ; WAY+CBD: 76.29 $\pm 21.36 ; p=0.002$ ). CBD, in all tested doses, as well as WAY100635 and AM251, did not induce locomotor changes. These findings suggest that $C B D$ decreases aggressive behaviors in mice and allow us to suggest that this effect involves $\mathrm{CB} 1$ and $5-\mathrm{HT} 1 \mathrm{~A}$ receptors. Therefore, this phytocannabinoid may be therapeutically useful to treat aggressive behaviors that are usually associated with psychiatric disorders.

Key-words: Cannabidiol, Agressiveness, Resident-Intruder, CB1 Receptor, 5-HT1A Receptor. 
Sumário 


\section{SUMÁRIO}

1 INTRODUÇÃO .20

\section{OBJETIVOS}

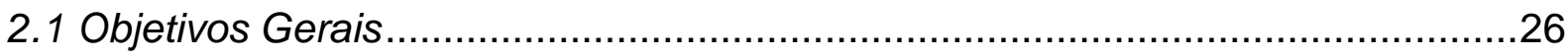

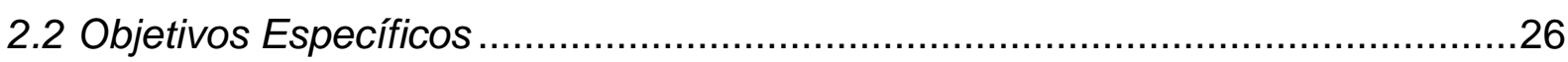

\section{MATERIAL E MÉTODOS}

3.1 Animais. .28

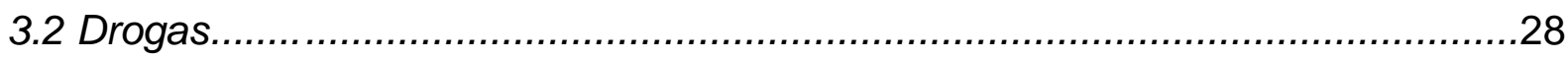

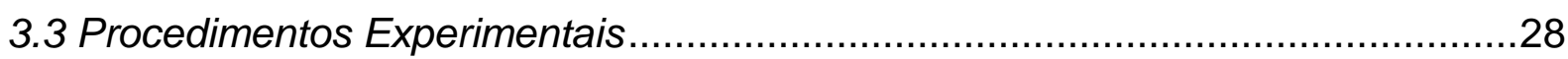

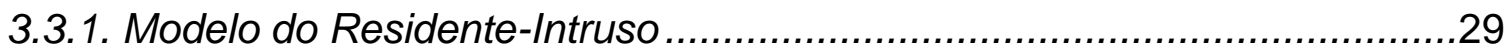

3.3.2. Avaliação dos efeitos do CBD sobre as respostas comportamentais induzidas pelo modelo do residente-intruso

3.3.3. Construção das curvas dose-resposta para os antagonistas de receptores 5-HT1A (WAY100635) e CB1 (AM251)

3.3.4. Avaliação da participação de receptores 5-HT1A nos efeitos comportamentais induzidos pelo CBD no modelo do residente-intruso ...

3.3.5. Avaliação da participação de receptores CB1 nos efeitos comportamentais induzidos pelo CBD no modelo do residente-intruso .31

3.3.6. Atividade Locomotora 32

3.4 Análise Estatística 32

\section{RESULTADOS}

4.1. Efeitos do CBD sobre as respostas comportamentais induzidas pelo modelo do residente-intruso.

4.2. Efeitos do CBD sobre a atividade locomotora no teste do campo aberto.

4.3. Curva dose-resposta para antagonismo de receptores 5-HT1A (WAY100635).

4.4. Efeitos do WAY100635 sobre a atividade locomotora no teste do campo aberto 
4.5. Efeitos do pré-tratamento com WAY100635 no efeito antiagressivo do CBD....41

4.6. Curva dose-resposta para antagonismo de receptores CB1

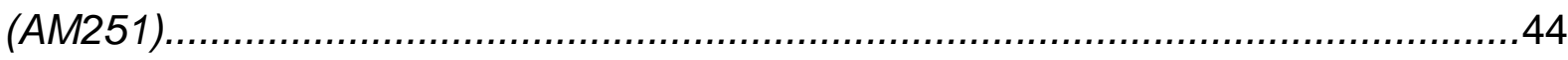

4.7. Efeitos do AM251 sobre a atividade locomotora no teste do campo aberto.......46

4.8. Efeitos do pré-tratamento com AM251 no efeito antiagressivo do CBD............47

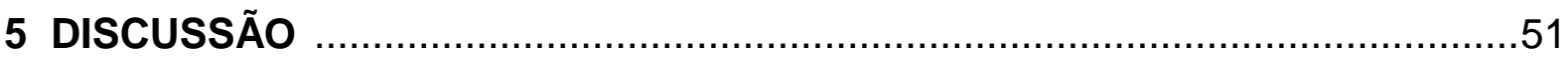

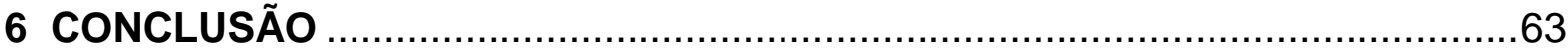

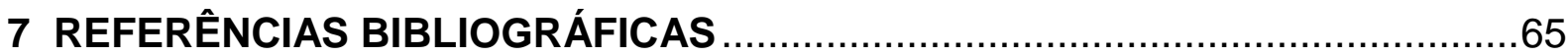


Introdução 


\section{INTRODUÇÃO}

A agressão é um comportamento social individual ou coletivo que possui valor adaptativo e compreende sinais de comunicação, atos e posturas para atingir um objetivo específico, geralmente na defesa contra estímulos ameaçadores (ARCHER, 2009; DE ALMEIDA; CABRAL; NARVAES, 2015; MICZEK et al., 2002; VAN HONK et al., 2010). Desse modo, a agressão é executada com o objetivo de causar dano ou prejuízo ao indivíduo agredido (BERKOWITZ, 1993). Diversos são os fatores que podem motivar este comportamento, como a competição por comida, busca por um parceiro sexual, defesa de território e/ou da prole, medo e frustração (MICZEK et al., 2001; TAKAHASHI et al., 2011).

O comportamento agressivo inadequado relaciona-se com transtornos mentais e sociais (FERRIS et al., 2008). Segundo o Manual Diagnóstico e Estatístico de Transtornos Mentais, na sua quinta edição (DSM-V), o comportamento agressivo é um sintoma (podendo estar presente ou não) em diversos transtornos psiquiátricos como esquizofrenia, transtornos de ansiedade, transtorno de adaptação, transtorno de controle dos impulsos, transtorno de personalidade antissocial, transtorno de atenção e hiperatividade, autismo e adicção (ASSOCIAÇÃO AMERICANA DE PSIQUIATRIA, 2013). O comportamento impulsivo é intimamente associado à agressão, visto que comportamentos impulsivos e agressivos precoces parecem predizer comportamentos agressivos e criminosos tardiamente (FARRINGTON, 1989).

Em roedores, o isolamento social tem sido amplamente utilizado para estudo de comportamentos agressivos (MALICK, 1979; MICZEK et al., 2001), visto que este procedimento aumenta a agressão nos animais residentes (isolados) em 
direção a um intruso colocado em sua caixa-moradia (BRAIN, 1975). Esta condição, denominada agressão induzida por isolamento, pode ser atenuada por drogas ansiolíticas (SAKAUE et al., 2001; SAKAUE et al., 2002) e antidepressivas (NELSON, M.; PINNA, 2011; PINNA et al., 2003; SANCHEZ et al., 1993). Neste modelo, a medida da latência para iniciar o primeiro ataque, o número de encontros agressivos, bem como a duração de tais encontros são medidas do comportamento agressivo per se (BRUNNER; HEN, 1997; LISBOA et al., 2007). Além disso, também tem sido sugerido que a medida da latência para iniciar o primeiro ataque agressivo pode ser usada como uma medida de impulsividade ou controle inibitório, uma vez que o aumento nesta latência indica inibição da tendência de iniciar o encontro agressivo (COPPENS et al., 2012).

Diversos neurotransmissores têm sido relacionados à agressão em humanos e em modelos animais - como a dopamina, o ácido gama-aminobutírico (GABA), o glutamato e, principalmente, a serotonina (5-HT) (DE ALMEIDA et al., 2015; GRAY et al., 2015; MICZEK et al., 2002; OLIVIER, 2015). Além disso, foi demonstrado que diversos peptídeos (fator liberador de corticotrofina, vasopressina, fator neurotrófico derivado do cérebro, neuropeptídeo $\mathrm{Y}$, peptídeos opioidérgicos), mediadores endocanabinoides, enzimas (óxido nítrico sintase neuronial e endotelial, monoaminoxidase A - MAO-A) e receptores (canabinoides do tipo 1, ocitocinérgicos, dentre outros) parecem estar envolvidos em modelos de agressão em roedores por atuar direta ou indiretamente sobre o sistema serotoninérgico (MICZEK et al., 2001; RODRIGUEZ-ARIAS et al., 2013; TAKAHASHI et al., 2011).

O sistema serotoninérgico é o mais amplamente estudado e o que parece ter maior envolvimento em comportamentos agressivos em roedores (GRAY et al., 
2015; MICZEK et al., 2002; MICZEK et al., 2001; OLIVIER, 2015) e humanos (DE ALMEIDA et al., 2015). Sabe-se que o aumento dos níveis de serotonina atenua comportamentos agressivos em animais e humanos, de modo que a impulsividade e os altos índices de agressividade estão correlacionados com baixos níveis de serotonina no cérebro de roedores. De modo geral, a ativação local de receptores 5HT1A e 5-HT1B em determinadas regiões cerebrais (área pré-óptica medial, núcleos dorsal e medial da rafe, amígdala, núcleo septal lateral, córtex orbitofrontal e préfrontal, hipotálamo anterior e medial, substância cinzenta periaquedutal) promovem a redução de comportamentos agressivos em diferentes protocolos experimentais e linhagens/espécies de animais (TAKAHASHI et al., 2011). Portanto, ferramentas farmacológicas que aumentem os níveis de 5-HT cerebrais (precursores serotoninérgicos, inibidores da recaptação de 5-HT) ou agonistas de receptores 5HT1A e 5-HT1B podem reduzir comportamentos agressivos em roedores e humanos. Entretanto, alguns trabalhos evidenciam que essa diminuição da agressão se dá através de inibição da atividade locomotora, sedação, comportamento estereotipado e redução da interação social (DE BOER; KOOLHAAS, 2005; MICZEK; HUSSAIN; FACCIDOMO, 1998; OLIVIER et al., 1995). Desse modo, drogas que consigam atenuar comportamentos agressivos sem alterações psicomotoras são alvos de interesse.

O canabidiol (CBD) é o principal constituinte não-psicotomimético da planta Cannabis sativa e possui ação sobre diversos receptores no sistema nervoso central (SNC), dentre eles CB1, CB2, GPR55 (G-protein coupled receptor 55), TRPV1 (transient receptor potential vanilloid type 1) e 5-HT1A (AHRENS et al., 2009; BISOGNO et al., 2001; CAMPOS; GUIMARAES, 2008;2009; DE PETROCELLIS et al., 2008; RESSTEL et al., 2009; RUSSO et al., 2005; RYBERG et al., 2007; 
THOMAS et al., 2007). Além de interagir com estes receptores, o CBD pode inibir a enzima hidrolase amida de ácidos graxos (FAAH-fatty acid amide hydrolase), responsável pelo metabolismo do canabinoide endógeno anandamida (AEA), portanto aumenta os níveis deste endocanabinoide (ECB). Desse modo, embora a afinidade do CBD pelos receptores CB1 e CB2 seja baixa, o CBD pode facilitar a sinalização ECB através da inibição da FAAH (BISOGNO et al., 2001) e, portanto, seus efeitos poderiam ser mediados por essa via (ativação de receptores canabinóides).

Os usos terapêuticos do CBD em transtornos mentais ou a eficácia em modelos animais destes transtornos já foram descritos (CAMPOS; MOREIRA; et al., 2012). Dentre estes, podem ser destacados a atenuação das consequências comportamentais do estresse agudo (CAMPOS; FERREIRA; GUIMARAES, 2012; RESSTEL et al., 2009) e efeito tipo-antidepressivo (ZANELATI et al., 2010) em roedores; efeito antipsicótico em humanos (ZUARDI; RODRIGUES; CUNHA, 1991) e em modelos animais (PEDRAZZI et al., 2015); efeitos ansiolíticos em modelos animais (GUIMARAES et al., 1990; MOREIRA; AGUIAR; GUIMARAES, 2006) e em humanos (BERGAMASCHI et al., 2011; CRIPPA et al., 2011; ZUARDI et al., 1993); e efeitos anti-compulsivos em modelos animais (CASAROTTO et al., 2010). Entretanto, o efeito do CBD em comportamentos agressivos é desconhecido.

Embora em alguns destes trabalhos citados acima o efeito do CBD envolva receptores CB1 (CASAROTTO et al., 2010), a atenuação das consequências comportamentais em situações de estresse agudo parece envolver a sinalização serotoninérgica, via ativação de receptores 5-HT1A (CAMPOS; FERREIRA; et al., 2012; RESSTEL et al., 2009; ZANELATI et al., 2010). Em relação ao sistema ECB, trabalhos prévios demonstraram que animais com deleção genética de receptores 
CB1 apresentam comportamentos pró-agressivos (MARTIN et al., 2002; RODRIGUEZ-ARIAS et al., 2013), além de aumento do RNAm da enzima catecol-Ometil transferase (COMT) nos núcleos mediano e dorsal da rafe e amígdala, bem como aumento do RNAm da enzima MAO-A também na amígdala (RODRIGUEZARIAS et al., 2013). Tais observações sugerem que, na ausência da sinalização via CB1, o possível aumento na expressão e atividade destas enzimas levaria à redução dos níveis de monoaminas, incluindo a 5-HT e, portanto, ao comportamento agressivo.

Diante do exposto, a hipótese deste trabalho é que a administração sistêmica de CBD diminuiria comportamentos tipo-agressivos induzidos pelo isolamento social em camundongos por facilitar a neurotransmissão via receptores 5-HT1A e/ou CB1. 
Objetivos 


\section{OBJETIVOS}

\subsection{Objetivo geral}

Avaliar o efeito da administração aguda de CBD sobre as consequências comportamentais no modelo de agressão induzida por isolamento social (modelo do residente-intruso) e os possíveis mecanismos de ação do CBD envolvidos neste efeito.

\subsection{Objetivos específicos}

A - Verificar se o tratamento sistêmico agudo com o CBD é capaz de atenuar comportamentos agressivos;

B - Investigar o envolvimento dos receptores 5-HT1A e/ou CB1 nos efeitos induzidos pelo CBD; 


\section{Material e Métodos}




\section{MATERIAL E MÉTODOS}

\subsection{Animais}

Camundongos Suíços machos (5-6 semanas de idade) provenientes do Biotério Central da USP-Ribeirão Preto foram alocados em grupos de 8 animais por gaiola (37,2 X 24,2 X 19,1 cm; Alesco, Brasil) e aclimatados no biotério do Departamento de Farmacologia da FMRP-USP por 1-2 semanas para chegarem à idade necessária para o início dos experimentos (animais adultos; 7-8 semanas). Os animais foram mantidos com água e comida ad libitum, sob ciclo claro-escuro de $12 \mathrm{~h}$ (luzes acesas às 6:30) e temperatura controlada $\left(24 \pm 1^{\circ} \mathrm{C}\right)$.

Os protocolos experimentais utilizados no presente projeto receberam aprovação da Comissão de Ética no uso de animais da Faculdade de Medicina de Ribeirão Preto da Universidade de São Paulo (Protocolo n. 038/2015).

\subsection{Drogas}

- Canabidiol (THC Pharma, Alemanha) utilizado sistemicamente nas doses de 5, 15, 30 e $60 \mathrm{mg} / \mathrm{kg}$. Veículo: 2\% Tween 80 em salina.

- WAY100635 (antagonista dos receptores 5-HT1A, Sigma, EUA) utilizado sistemicamente nas doses de 0,03;0,1;0,3; 1 e $3 \mathrm{mg} / \mathrm{kg}$. Veículo: Salina.

- AM251 (antagonista dos receptores CB1, Tocris, EUA) utilizado sistemicamente nas doses de 0,1;0,5; 1 e 1,5 mg/kg. Veículo: 10\% DMSO em salina.

Todas as drogas foram administradas em volume final de $10 \mathrm{ml} / \mathrm{kg}$.

\subsection{Procedimentos experimentais}




\subsubsection{Modelo do Residente-Intruso}

Dez dias antes do início dos experimentos, os camundongos a serem utilizados como residentes foram alocados em caixas individuais $(37,9 \times 19,7 \times 12,7 \mathrm{~cm}$; Alesco, Brasil) e, durante esse período, as gaiolas mantidas intactas (sem manuseio, troca de maravalha, comida ou ração). Os camundongos intrusos foram mantidos agrupados (8 animais/caixa) até o momento do teste em ambiente enriquecido com iglus, a fim de atenuar o desenvolvimento de comportamentos dominantes e agressivos. $O$ delineamento experimental pode ser observado na Fig. 1.

O teste foi realizado conforme descrito previamente (LISBOA et al., 2007). Os camundongos residentes possuíam peso corporal entre 30-40 g enquanto que os intrusos variavam no máximo $5 \mathrm{~g}$ em relação ao peso do residente. Após o período de isolamento, no dia do experimento, o camundongo intruso foi colocado na caixamoradia do camundongo residente e, durante $20 \mathrm{~min}$, as interações foram gravadas. Posteriormente, os seguintes comportamentos foram analisados manualmente, com auxílio de cronômetros, por um observador cego aos tratamentos:

- Latência para a primeira mordida: tempo, em segundos, decorrido entre a colocação do intruso e o momento da primeira mordida;

- Número total dos ataques: número de vezes que o residente ataca o intruso ou realiza movimentos de ameaça;

- Duração total dos episódios de ataque: tempo, em segundos, que os animais gastam em ameaças ou encontros agressivos.

Animais que não apresentaram comportamentos agressivos durante os 20 min de teste, foram considerados para análise estatística independentemente do 
grupo experimental ao qual pertenciam. Animais residentes que foram agredidos por animais intrusos não foram considerados para análise estatística.

\section{Delineamento Experimental}

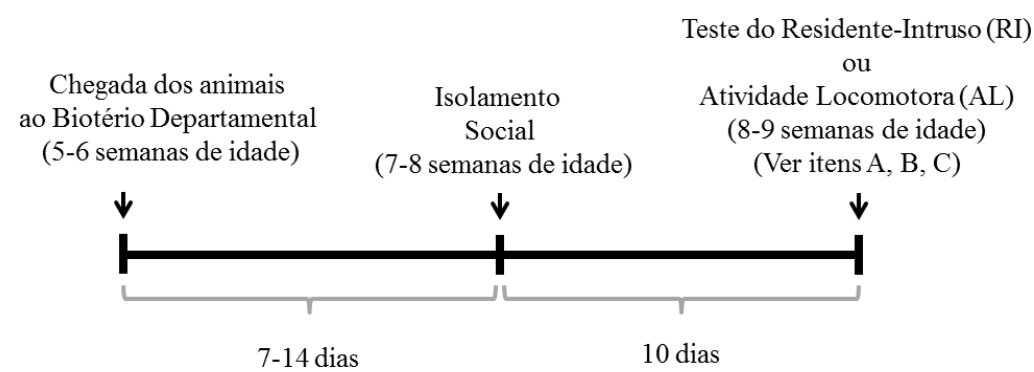

$\underline{\text { A. Construcão da curva dose-resposta para o CBD }}$

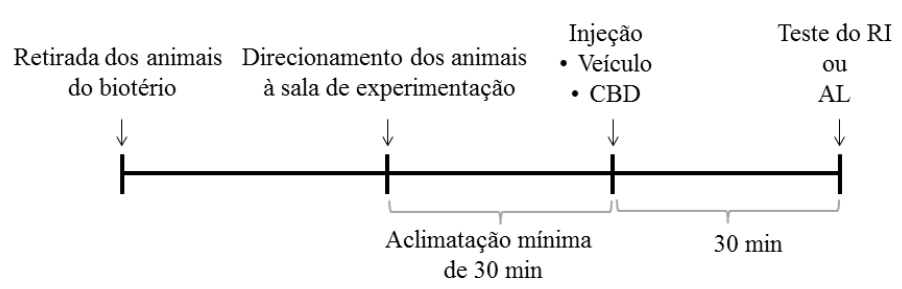

B. Construção da curva dose-resposta para antagonistas dos receptores 5-HT1A ou CB1

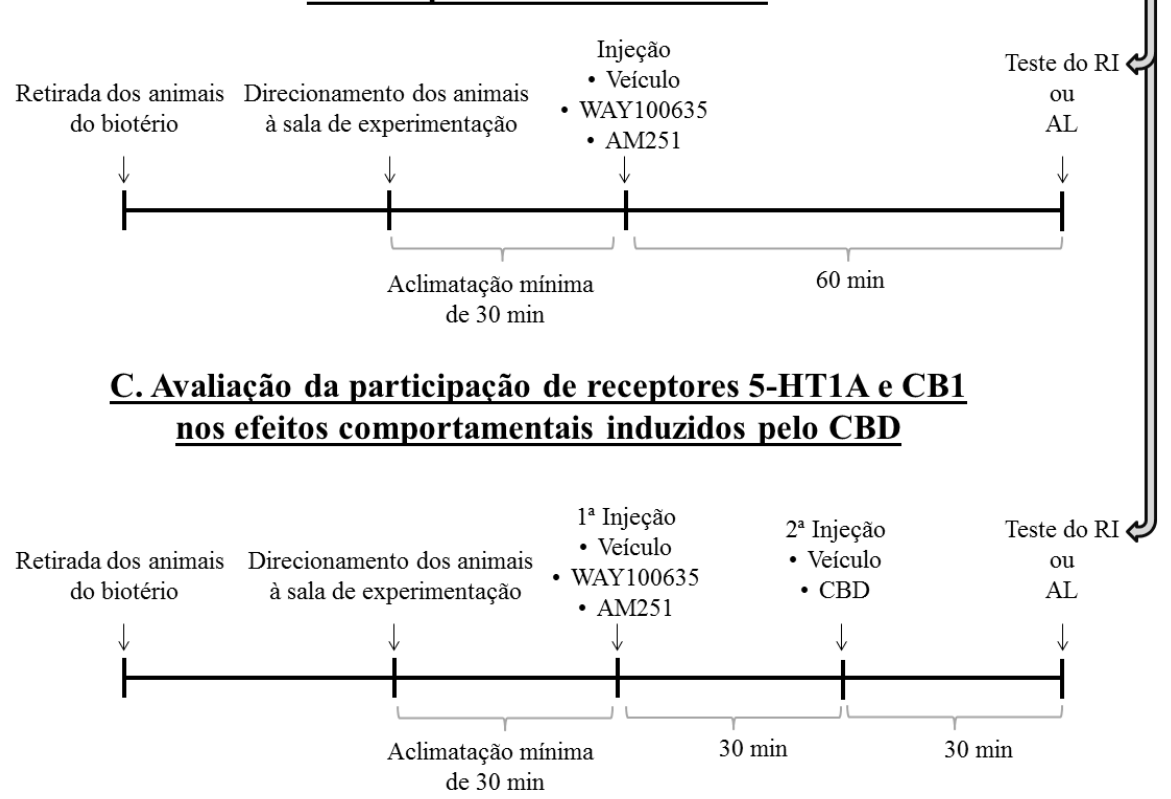

Figura 1. Delineamento experimental proposto para avaliação dos efeitos do CBD sobre comportamentos agressivos. CBD: canabidiol; $A L$ : atividade locomotora; RI: teste do residente-intruso. 


\subsubsection{Avaliação dos efeitos do CBD sobre as respostas comportamentais induzidas pelo modelo do residente-intruso}

Inicialmente, os animais residentes receberam 1 injeção intraperitoneal de CBD nas doses de 5, 15, 30 ou $60 \mathrm{mg} / \mathrm{kg}$ para realização de uma curva doseresposta. A administração ocorreu 30 min antes da realização do teste.

\subsubsection{Construção das curvas dose-resposta para os antagonistas de receptores 5-HT1A (WAY100635) e CB1 (AM251)}

Para a escolha de doses não efetivas dos antagonistas, foram construídas curvas dose-resposta a partir da administração de injeções intraperitoneais de WAY100635 nas doses de 0,03;0,1;0,3; 1 e $3 \mathrm{mg} / \mathrm{kg}$ ou AM251 nas doses de 0,1; 0,5; 1 e 1,5 mg/kg. A administração ocorreu $1 \mathrm{~h}$ antes da realização do teste.

\subsubsection{Avaliação da participação de receptores 5-HT1A nos efeitos comportamentais induzidos pelo CBD no modelo do residente-intruso}

Para avaliação da possível participação dos receptores 5-HT1A nos efeitos do CBD, foram administradas duas injeções intraperitoneais com um intervalo de 30 min entre as mesmas. A primeira injeção consistiu de WAY100635 (0,3 mg/kg), antagonista dos receptores 5-HT1A, ou veículo; e a segunda, de CBD (15 mg/kg) ou veículo. O teste foi realizado 30 min após a última injeção.

\subsubsection{Avaliação da participação de receptores CB1 nos efeitos comportamentais induzidos pelo CBD no modelo do residente-intruso}

Para avaliação da possível participação dos receptores CB1 nos efeitos do CBD, foram administradas duas injeções intraperitoneais com um intervalo de 30 min entre as mesmas. A primeira injeção consistiu de AM251 (1 mg/kg), antagonista dos 
receptores CB1, ou veículo; e a segunda, de CBD (15 mg/kg) ou veículo. O teste foi realizado 30 min após a última injeção.

\subsubsection{Atividade Locomotora}

Para controlar possíveis efeitos motores das drogas, a atividade locomotora espontânea de cada animal (grupos independentes e mantidos isolados por 10 dias) foi avaliada individualmente em um actimetro fotoelétrico (Actitrack, Panlab, Barcelona, Espanha) durante 5 min. O aparato consiste em uma arena quadrada (45 x $45 \times 20 \mathrm{~cm}$ ) equipada com 16 fotocélulas que detectam movimentos horizontais e 16 fotocélulas que detectam movimentos verticais. Desse modo, a atividade locomotora foi obtida a partir do registro do número de interrupções das células fotoelétricas durante 5 min. Além da detecção fotoelétrica pelo actimetro, a imagem do animal testado foi capturada por uma câmera e analisada pelo programa ANY MAZE (Stoelting), que detectou a posição do animal na arena e calculou a distância total percorrida.

\subsection{Análise Estatística}

Os resultados comportamentais foram representados como média \pm E.P.M. e analisados por análise de variância (ANOVA) de uma ou duas vias, conforme o desenho experimental. Nos experimentos realizados para avaliar o envolvimento dos receptores 5-HT1A e CB1 nos efeitos do CBD, os dados foram analisados por ANOVA de duas vias utilizando a primeira e segunda injeção como fatores. Quando interações entre os fatores foram observadas, foi realizado ANOVA de uma via. As análises pós-teste foram realizadas pelo teste de Duncan. Em caso de violações significantes do pré-requisito de homocedasticidade foi empregada a análise não paramétrica de Kruskal-Wallis seguida, em caso de significância estatística, do teste 
de Mann-Whitney. O nível de significância estatístico utilizado foi de $95 \%(p<0,05)$ e a análise foi realizada com o auxílio do software SPSS (versão 20.0). 
$\underline{\text { Resultados }}$ 


\section{RESULTADOS}

\subsection{Efeitos do CBD sobre as respostas comportamentais induzidas}

\section{pelo modelo do residente-intruso}

Apesar da tendência gráfica, a injeção de CBD não foi capaz de aumentar, estatisticamente, a latência de ataque do residente frente ao intruso em comparação com o grupo veículo [Fig. $2\left(X^{2}=7,34\right.$, g.l.=4; $p=0,119$; Kruskal Wallis)].

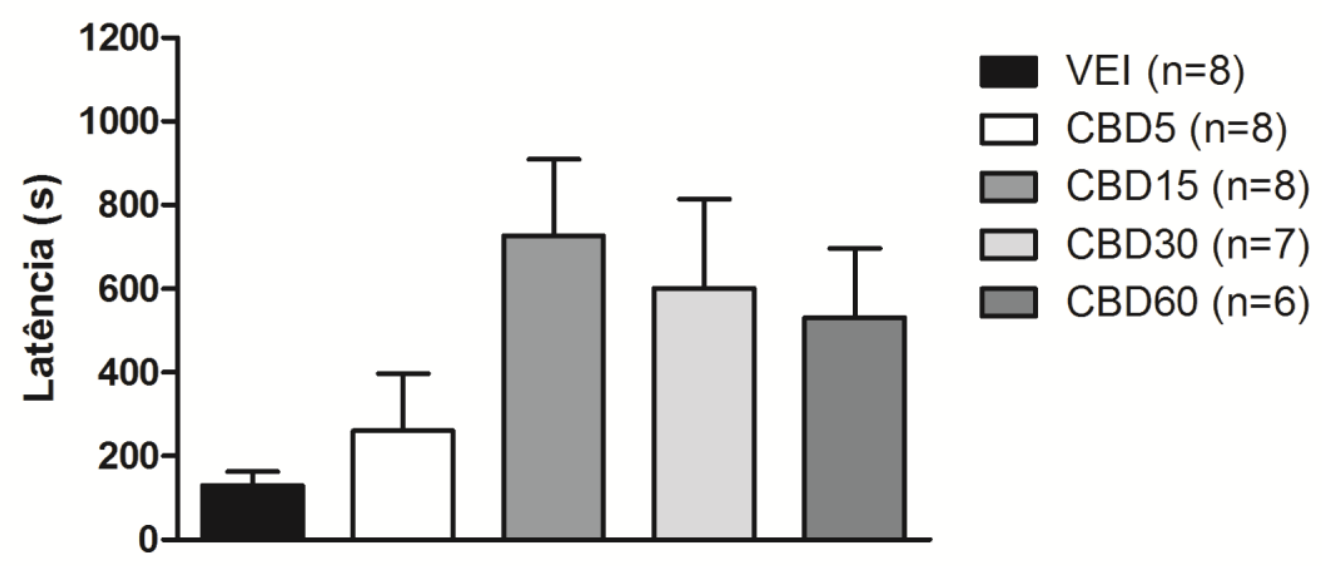

Figura 2. O Canabidiol não aumentou a latência para o primeiro ataque em direção ao intruso. Camundongos Suíços foram mantidos isolados por 10 dias. Os animais receberam uma injeção de veículo ou CBD (30 min antes do teste) e a latência (tempo em segundos) para primeira mordida em direção ao intruso foi avaliada durante $20 \mathrm{~min}$. Dados apresentados como Média \pm E.P.M., $n=6-8$ animais/grupo. $p>0,05$, obtido pelo teste de Kruskal Wallis.

Com relação ao número total de ataques, as quatro doses de CBD testadas foram efetivas em reduzir esse parâmetro quando comparadas ao grupo veículo [Fig. $3\left(F_{4,32}=5,59 ; p=0,002 ;\right.$ ANOVA de uma via seguida pelo pós-teste de Duncan)]. 


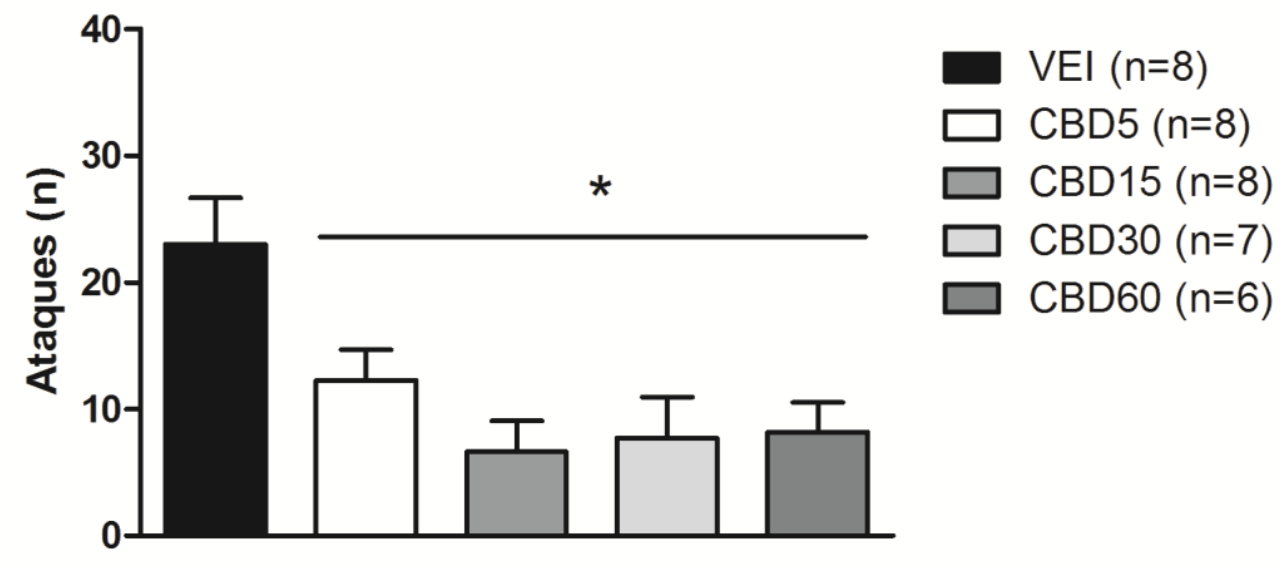

Figura 3. 0 Canabidiol $(5-60 \mathrm{mg} / \mathrm{kg})$ diminuiu o número total de ataques do residente frente ao intruso. Camundongos Suíços foram mantidos isolados por 10 dias. Os animais receberam uma injeção de veículo ou CBD (30 min antes do teste) e o número total de ataques em direção ao intruso foi avaliado durante $20 \mathrm{~min}$. Dados apresentados como Média \pm E.P.M., $n=6-8$ animais/grupo. ${ }^{*} p<0,05$ em relação ao grupo veículo, obtido pelo teste ANOVA de uma via seguido pelo pós-teste de Duncan.

Já o tempo total de ataques foi atenuado após administração das doses intermediárias de CBD (15 e 30 mg/kg) [Fig. $4\left(F_{4,32}=3,49 ; p=0,018\right.$; ANOVA de uma via seguida pelo pós-teste de Duncan)].

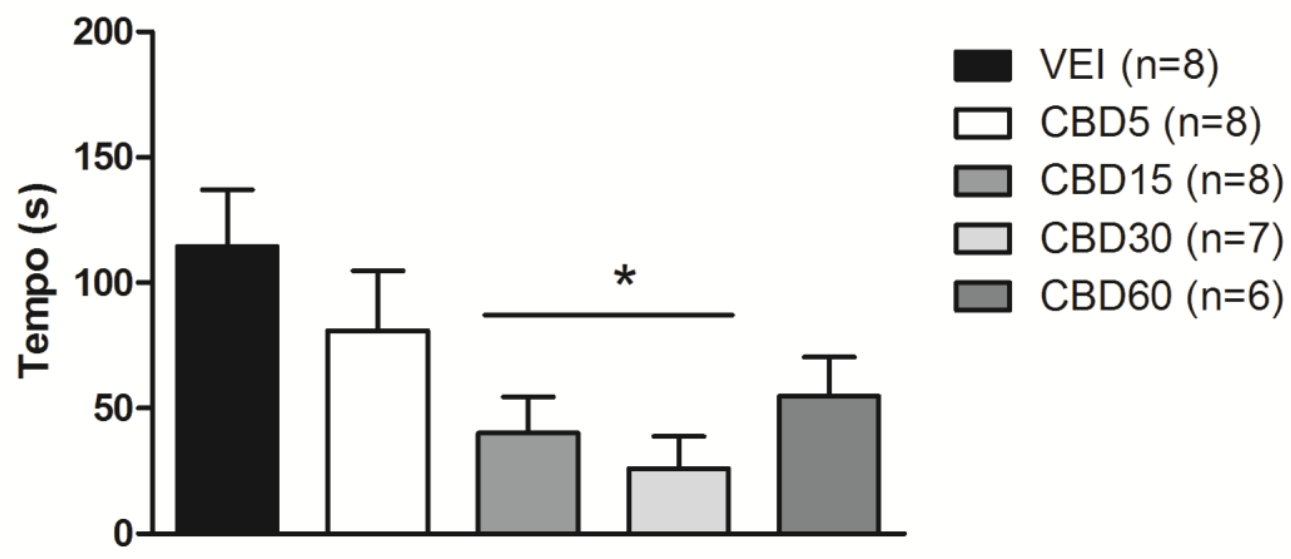

Figura 4. O Canabidiol ( $15 \mathrm{e} 30 \mathrm{mg} / \mathrm{kg}$ ) diminuiu o tempo total de ataques do residente frente ao intruso. Camundongos Suíços foram mantidos isolados por 10 dias. Os animais receberam uma injeção de veículo ou CBD (30 min antes do teste) e o tempo total de ataques, em segundos, direcionado ao intruso foi avaliado durante $20 \mathrm{~min}$. Dados apresentados como Média \pm E.P.M., $n=6-8$ animais/grupo. ${ }^{*} \mathrm{p}<0,05$ em relação ao grupo veículo, obtido pelo teste ANOVA de uma via seguido pelo pós-teste de Duncan. 
4.2. Efeitos do CBD sobre a atividade locomotora no teste do campo aberto

A injeção de CBD, 30 minutos antes do teste, não induziu quaisquer alterações locomotoras nos parâmetros avaliados: Distância Total Percorrida (m) [Fig. 5A $\left(F_{4,20}=2,62 ; p=0,066\right) ; A N O V A$ de uma via)] e Atividade Total (no de interrupções) [Fig. 5B ( $\left.F_{4,20}=0,47 ; p=0,754\right)$; ANOVA de uma via)].

A.

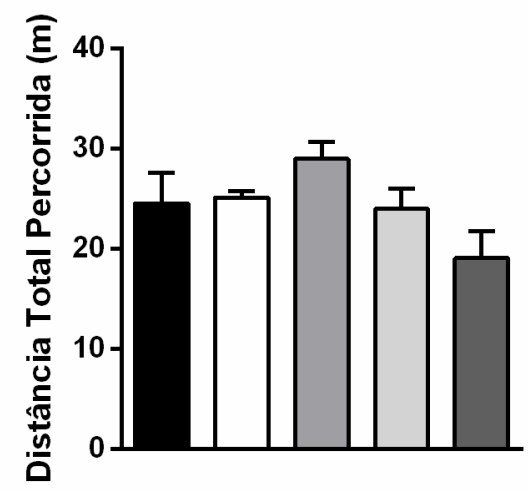

B.

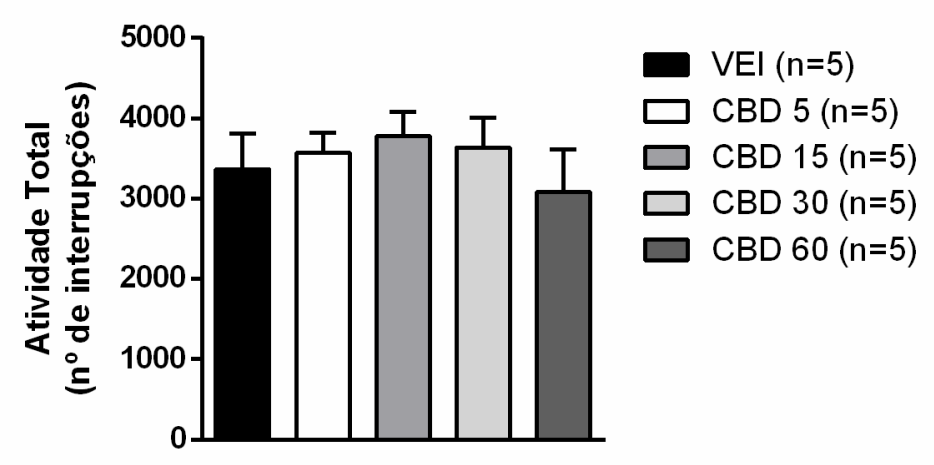

Figura 5. O Canabidiol não possui efeitos sobre atividade locomotora. Camundongos Suíços foram mantidos isolados por 10 dias. Os animais receberam uma injeção de veículo ou CBD (30 min antes do teste) e foram submetidos ao teste do campo aberto por 5 min para avaliação da atividade locomotora. A. Distância total percorrida (em metros) pelo animal na arena durante o teste; B. Número de interrupções do infravermelho pelo animal durante $o$ teste. Dados apresentados como Média \pm E.P.M., $n=5$ animais/grupo. $p>0,05$ em relação ao grupo veículo, obtido pelo teste ANOVA de uma via. 


\subsection{Curva dose-resposta para antagonismo de receptores 5-HT1A (WAY100635)}

A injeção de WAY100635 não foi capaz de alterar a latência de ataque do residente frente ao intruso em comparação com o grupo veículo [Fig. $6\left(F_{5,36}=0,63\right.$; $\mathrm{p}=0,675 ;$ ANOVA de uma via)].

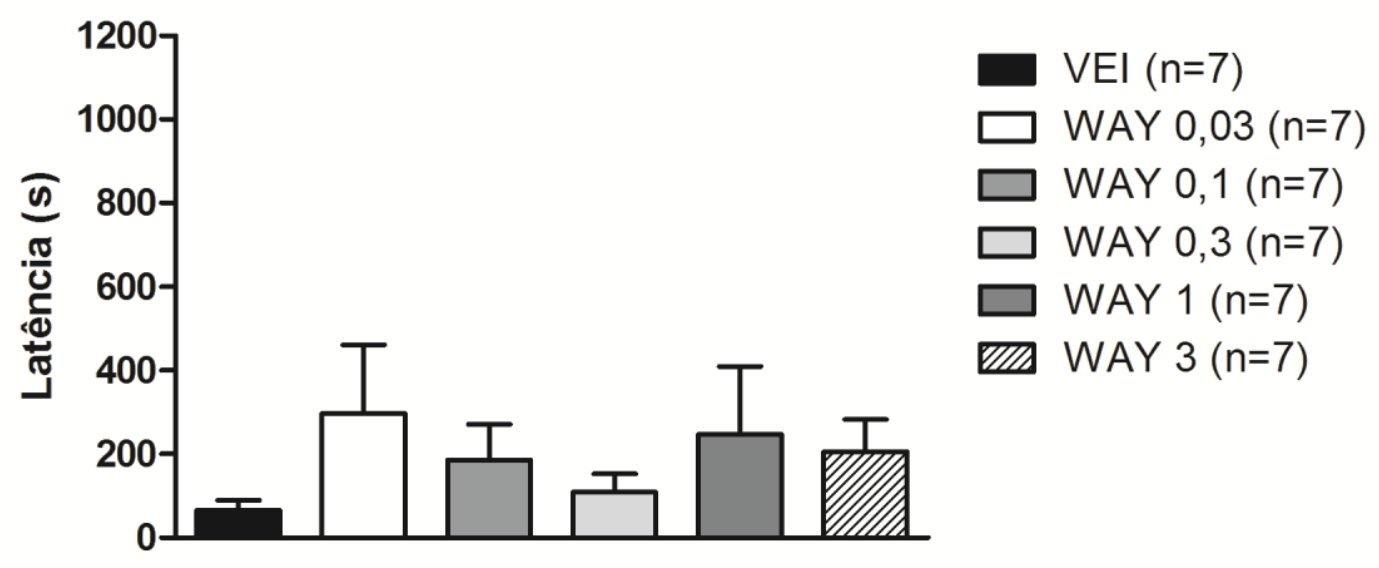

Figura 6. O WAY100635 não altera a latência para primeira mordida em direção ao intruso. Camundongos Suíços foram mantidos isolados por 10 dias. Os animais receberam uma injeção de veículo ou WAY100635 (60 min antes do teste) e a latência, tempo em segundos, para primeira mordida em direção ao intruso foi avaliada durante 20 min. Dados apresentados como Média \pm E.P.M., $n=7$ animais/grupo. $p>0,05$ em relação ao grupo veículo, obtido pelo teste ANOVA de uma via.

As cinco doses testadas de WAY100635 não foram efetivas em alterar o número de ataques quando comparadas ao grupo veículo [Fig. $7 \quad\left(F_{5,36}=0,44\right.$; $\mathrm{p}=0,817 ;$ ANOVA de uma via)]. 


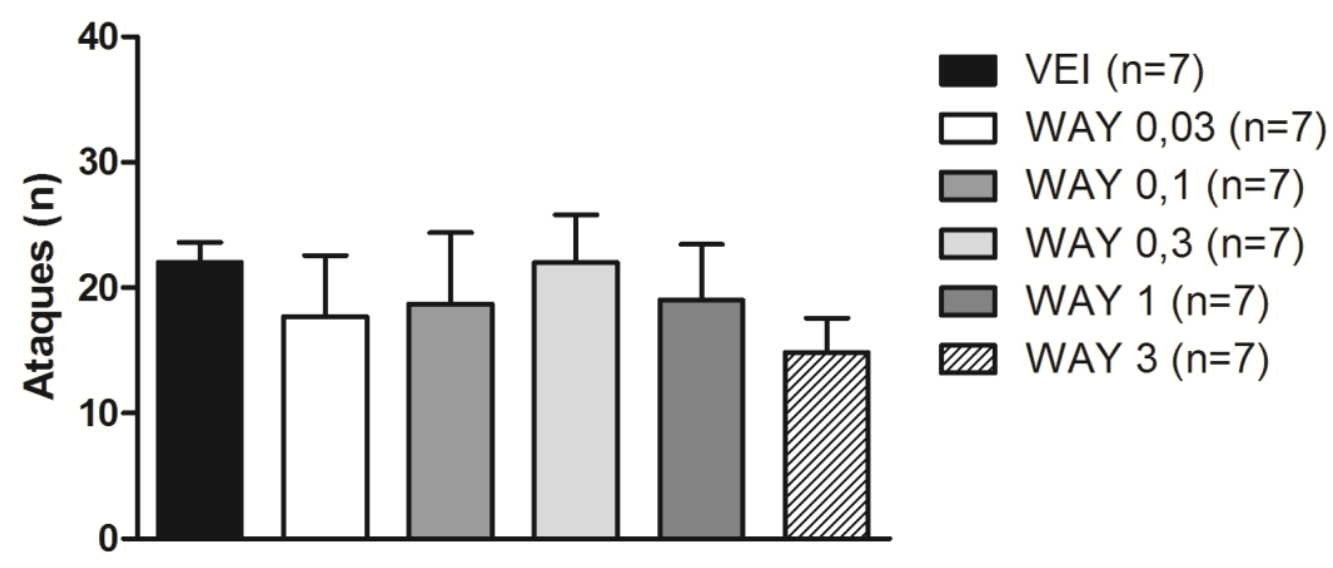

Figura 7. O WAY100635 não altera o número total de ataques do residente frente ao intruso. Camundongos Suíços foram mantidos isolados por 10 dias. Os animais receberam uma injeção de veículo ou WAY100635 (60 min antes do teste) e o número total de ataques em direção ao intruso foi avaliado durante $20 \mathrm{~min}$. Dados apresentados como Média \pm E.P.M., $n=7$ animais/grupo. $p>0,05$ em relação ao grupo veículo, obtido pelo teste ANOVA de uma via.

O tempo total de ataques também não sofreu alteração frente à administração de WAY100635 [Fig. $8\left(F_{5,36}=1,43 ; p=0,236 ;\right.$ ANOVA de uma via)].

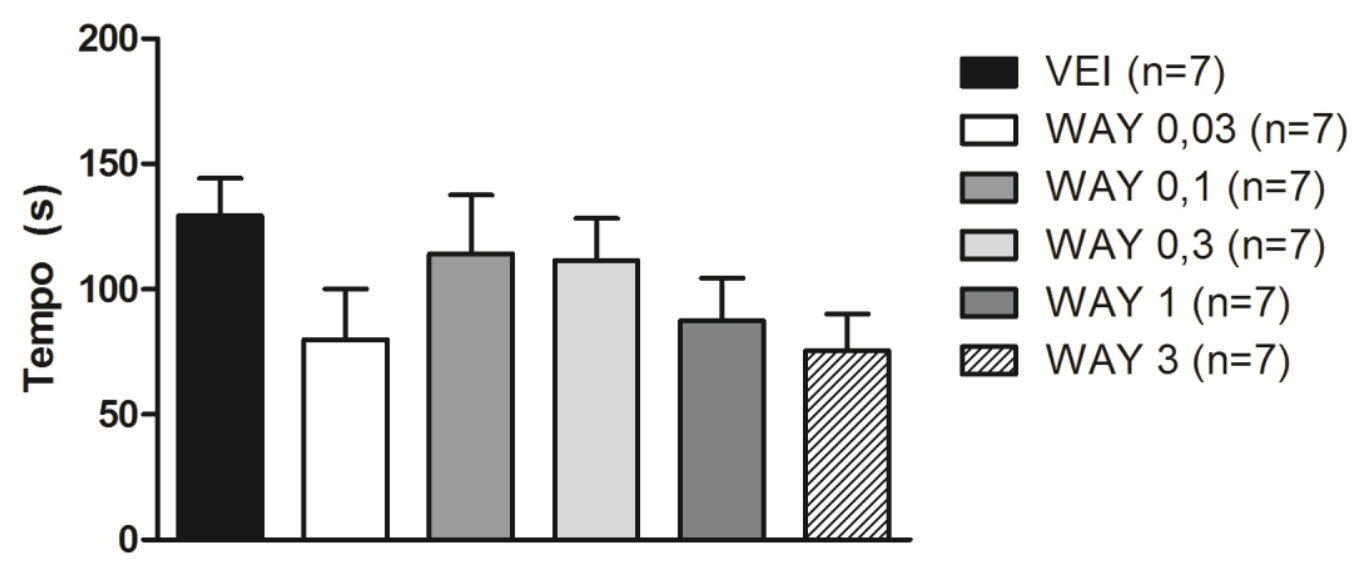

Figura 8. O WAY100635 não altera o tempo total de ataques do residente frente ao intruso. Camundongos Suíços foram mantidos isolados por 10 dias. Os animais receberam uma injeção de veículo ou WAY100635 (60 min antes do teste) e o tempo total de ataques (em segundos) direcionado ao intruso foi avaliado durante $20 \mathrm{~min}$. Dados apresentados como Média \pm E.P.M., $n=7$ animais/grupo. $\mathrm{p}>0,05$ em relação ao grupo veículo, obtido pelo teste ANOVA de uma via. 


\subsection{Efeitos do WAY100635 sobre a atividade locomotora no teste do} campo aberto

A injeção de WAY100635, 60 minutos antes do teste, não induziu quaisquer alterações locomotoras nos parâmetros avaliados: Distância Total Percorrida (m) [Fig. 9A $\left(F_{5,25}=1,71 ; p=0,170 ;\right.$ ANOVA de uma via)] e Atividade Total ( $n^{\circ}$ de interrupções) [Fig. 9B ( $F_{5,25}=1,28 ; p=0,305 ;$ ANOVA de uma via)].

A.

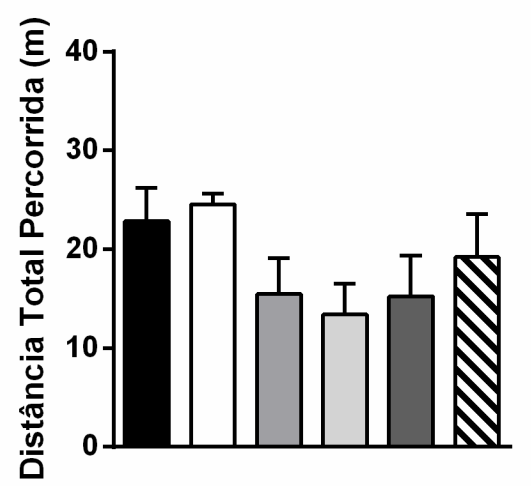

B.

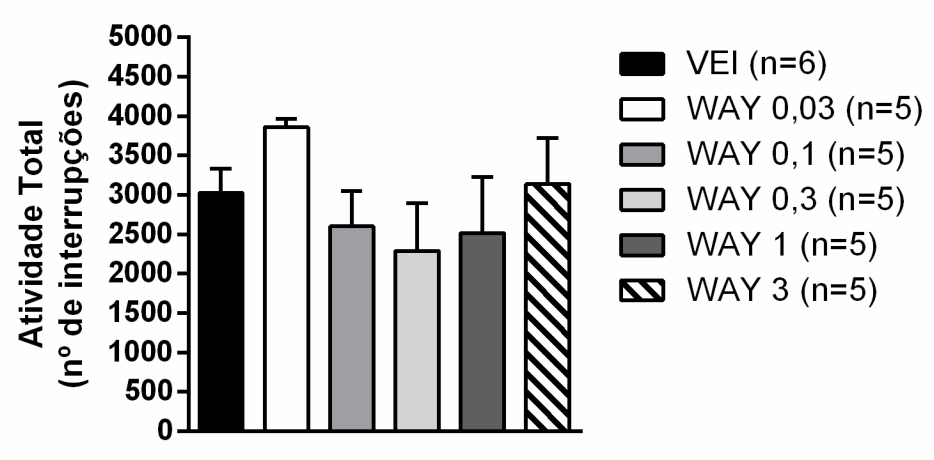

Figura 9. O WAY100635 não possui efeitos sobre atividade locomotora. Camundongos Suíços foram mantidos isolados por 10 dias. Os animais receberam uma injeção de veículo ou WAY100635 (60 min antes do teste) e foram submetidos ao teste do campo aberto por 5 min para avaliação da atividade locomotora. A. Distância total percorrida (em metros) pelo animal na arena durante o teste; B. Número de interrupções do infravermelho pelo animal durante $o$ teste. Dados apresentados como Média \pm E.P.M., $n=5-6$ animais/grupo. p>0,05 em relação ao grupo veículo, obtido pelo teste ANOVA de uma via. 


\subsection{Efeitos do pré-tratamento com WAY100635 no efeito anti- agressivo do CBD}

A administração prévia de WAY100635 foi capaz de bloquear ou atenuar os efeitos anti-agressivos do CBD, evidenciando a participação dos receptores 5-HT1A nos mecanismos pelos quais essa droga exerce suas ações.

Houve interação entre as injeções $\left(F_{1,25}=5,93 ; p=0,022\right)$. O CBD $(15 \mathrm{mg} / \mathrm{kg})$ foi efetivo em aumentar a latência da primeira mordida e este efeito foi bloqueado pela administração prévia de WAY100635 (0,3 mg/kg) [Fig. $10\left(F_{3,25}=4,57 ; p=0,011\right.$; ANOVA de uma via seguida pelo pós-teste de Duncan)].

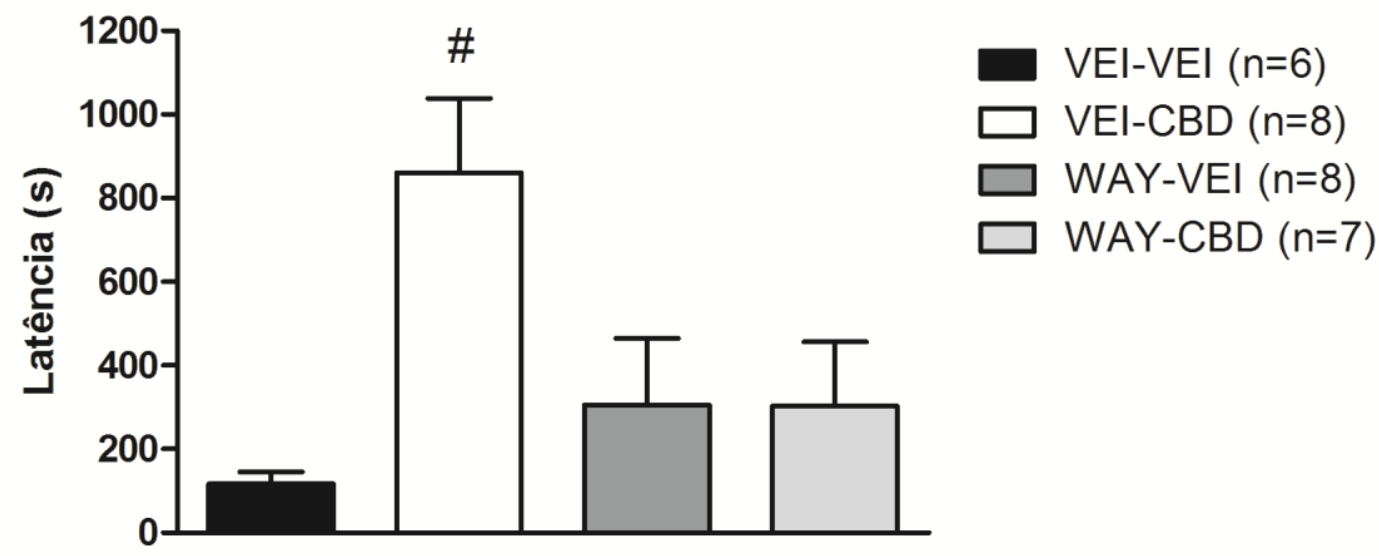

Figura 10. O WAY100635 bloqueia o efeito do CBD sobre a latência da primeira mordida. Camundongos Suíços foram mantidos isolados por 10 dias. Os animais receberam uma injeção de veículo ou WAY100635 (0,3 mg/kg; 60 min antes do teste) e, posteriormente, uma injeção de veículo ou CBD (15 mg/kg; $30 \mathrm{~min}$ antes do teste) e a latência (tempo em segundos) para primeira mordida em direção ao intruso foi avaliada durante 20 min. Dados apresentados como Média \pm E.P.M., $n=6-8$ animais/grupo. ${ }^{*} p<0,05$ em relação aos grupos veículo-veículo, WAY-veículo e WAY-canabidiol, obtido pelo teste ANOVA de uma via seguida pelo pós-teste de Duncan.

De modo semelhante ao resultado anterior, houve interação entre as injeções $\left(F_{1,25}=4,34 ; p=0,048\right)$. O CBD $(15 \mathrm{mg} / \mathrm{kg})$ foi capaz de reduzir o número de ataques e 
este efeito foi atenuado pelo pré-tratamento com o WAY100635 (0,3 mg/kg) [Fig. 11 $\left(F_{3,25}=2,82 ; p=0,059 ;\right.$ ANOVA de uma via seguida pelo pós-teste de Duncan, $\mathrm{p}<0,05)]$.

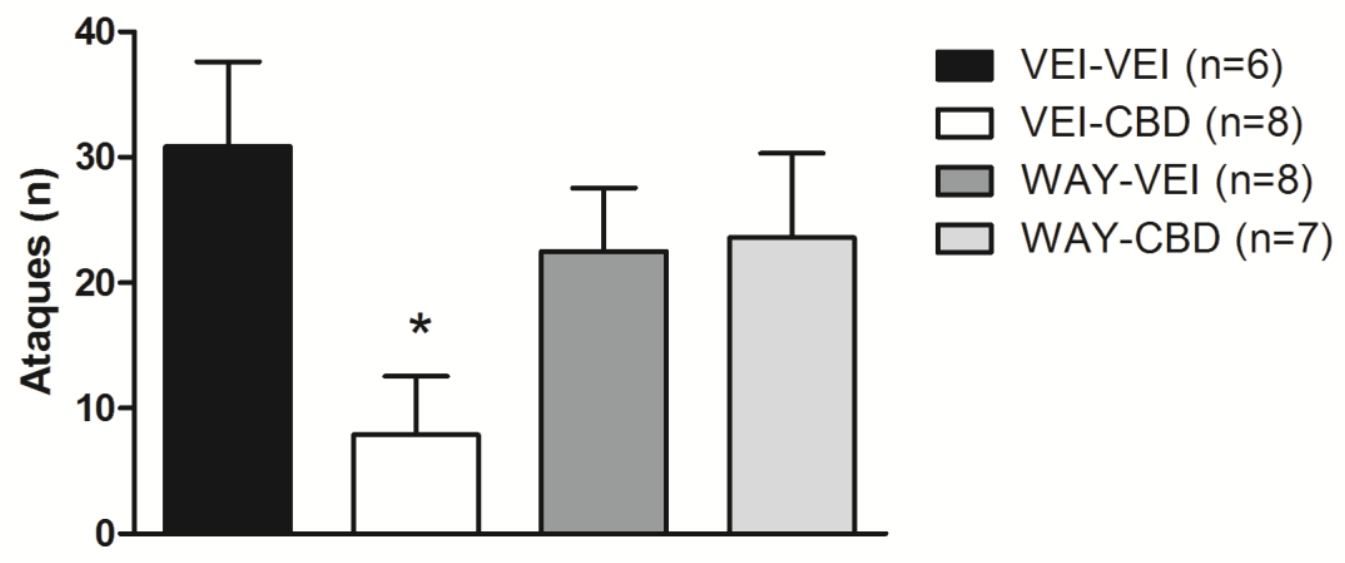

Figura 11. O WAY100635 atenua o efeito do CBD no número total de ataques do residente frente ao intruso. Camundongos Suíços foram mantidos isolados por 10 dias, receberam uma injeção de veículo ou WAY100635 (0,3 mg/kg; $60 \mathrm{~min}$ antes do teste) e, posteriormente, uma injeção de veículo ou CBD (15 mg/kg; $30 \mathrm{~min}$ antes do teste) e o número total de ataques em direção ao intruso foi avaliado durante $20 \mathrm{~min}$. Dados apresentados como Média \pm E.P.M., $n=6-8$ animais/grupo. ${ }^{*} \mathrm{p}<0,05$ em relação ao grupo veículo-veículo, obtido pelo teste ANOVA de uma via seguido pelo pós-teste de Duncan.

Novamente houve interação entre as injeções $\left(F_{1,25}=4,57 ; p=0,042\right)$. O CBD (15 mg/kg) foi capaz de reduzir o tempo total de ataques e este efeito foi atenuado pelo pré-tratamento com o WAY100635 (0,3 mg/kg) [Fig. $12\left(F_{3,25}=6,42 ; p=0,002\right.$; ANOVA de uma via seguida pelo pós-teste de Duncan)]. 


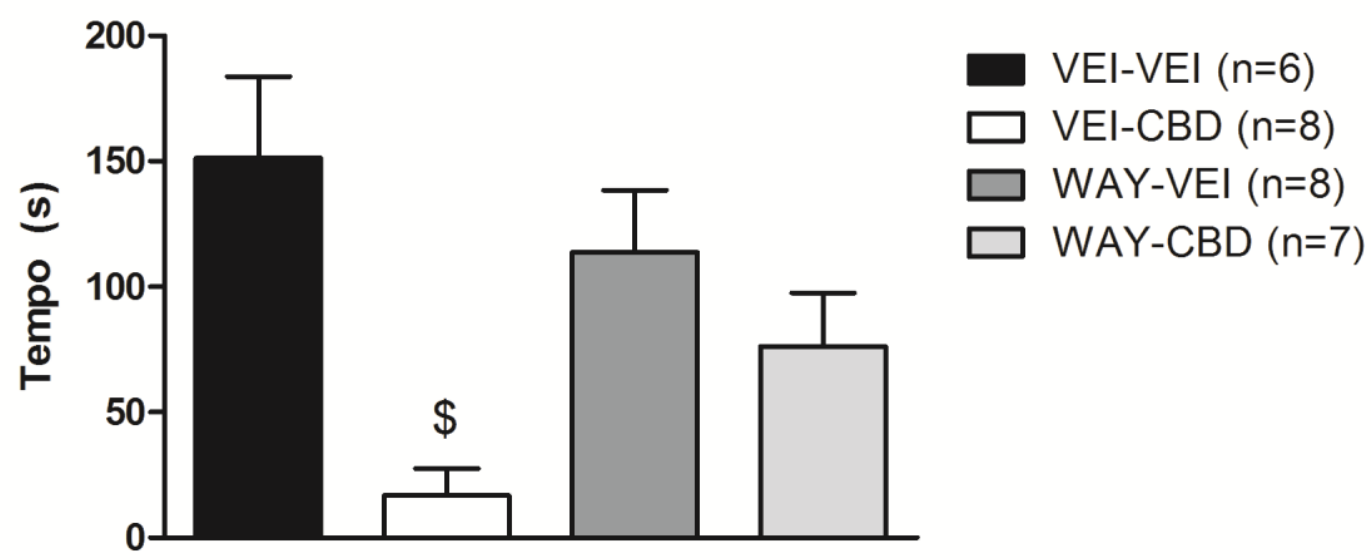

Figura 12. O WAY100635 atenua o efeito do CBD no tempo total de ataques do residente frente ao intruso. Camundongos Suíços foram mantidos isolados por 10 dias, receberam uma injeção de veículo ou WAY100635 (0,3 mg/kg; $60 \mathrm{~min}$ antes do teste) e, posteriormente, uma injeção de veículo ou CBD (15 mg/kg; 30 min antes do teste) e o tempo total de ataques (em segundos) direcionado ao intruso foi avaliado durante 20 min. Dados apresentados como Média \pm E.P.M., $n=6-8$ animais/grupo. ${ }^{\$} p<0,05$ em relação ao grupo veículo-veículo e WAY-veículo, obtido pelo teste ANOVA de uma via seguido pelo pós-teste de Duncan. 


\subsection{Curva dose-resposta para antagonismo de receptores CB1 (AM251)}

A injeção de AM251 não foi capaz de alterar a latência de ataque do residente frente ao intruso em comparação com o grupo veículo [Fig. $13\left(F_{4,24}=0,71 ; p=0,593\right.$; ANOVA de uma via)].

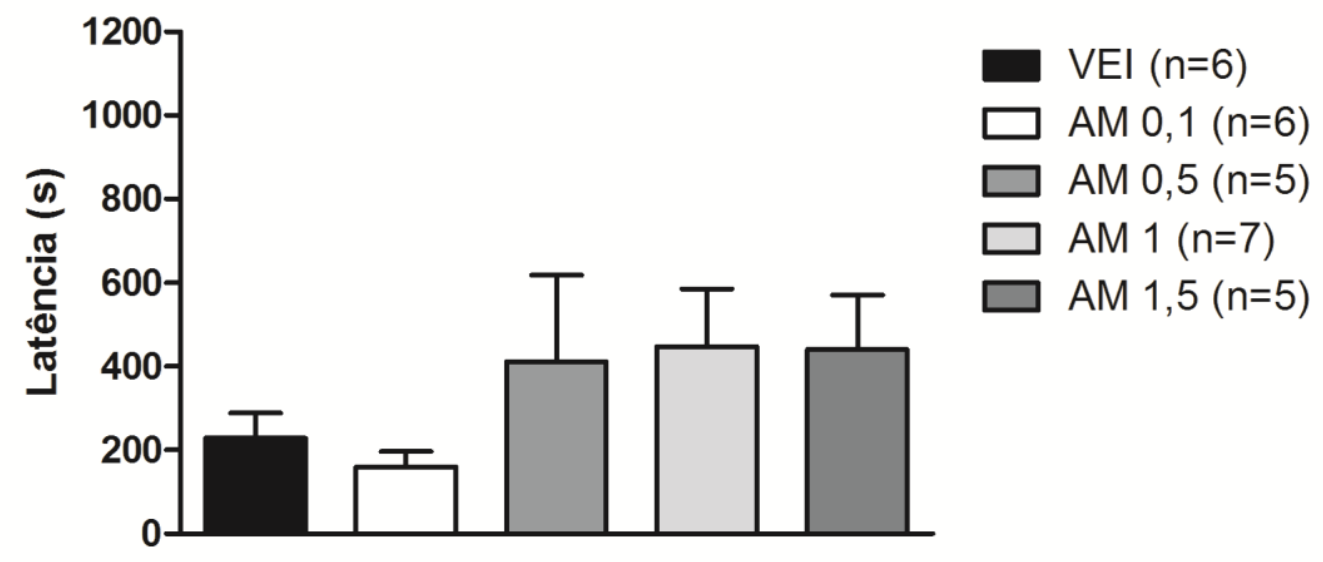

Figura 13. O AM251 não altera a latência para primeira mordida em direção ao intruso. Camundongos Suíços foram mantidos isolados por 10 dias. Os animais receberam uma injeção de veículo ou AM251 (60 min antes do teste) e a latência, tempo em segundos, para primeira mordida em direção ao intruso foi avaliada durante $20 \mathrm{~min}$. Dados apresentados como Média \pm E.P.M., $n=5-7$ animais/grupo. $p>0,05$ em relação ao grupo veículo, obtido pelo teste ANOVA de uma via.

As quatro doses testadas de AM251 não foram efetivas em alterar o número de ataques quando comparadas ao grupo veículo [Fig. $14\left(F_{4,24}=0,68 ; p=0,684\right.$; ANOVA de uma via)]. 


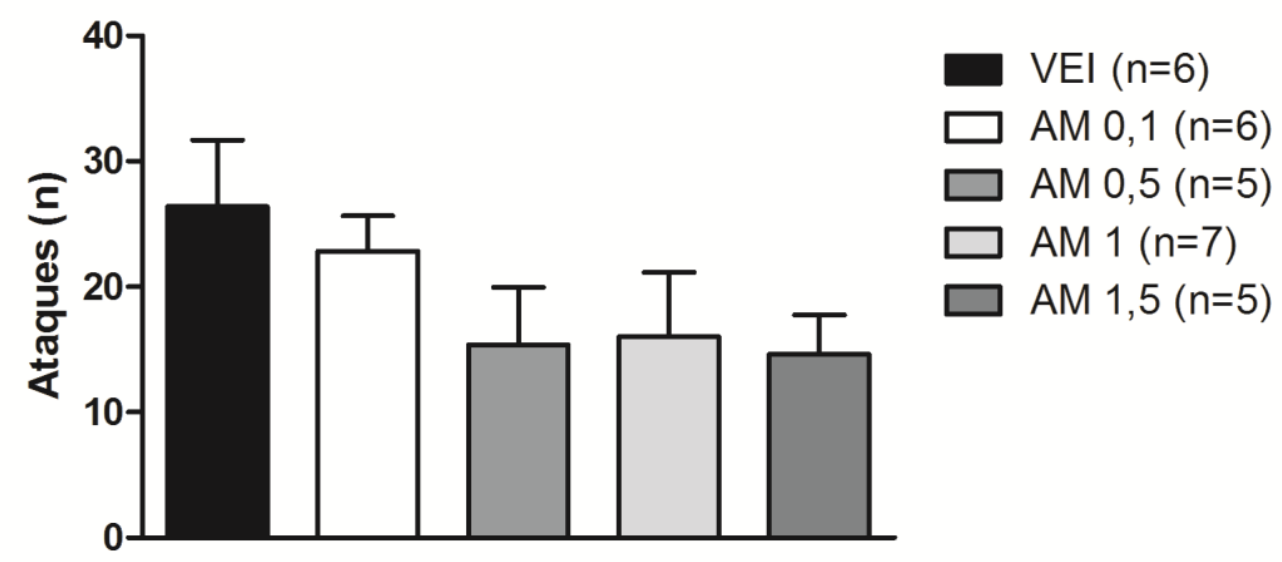

Figura 14. O AM251 não altera o número total de ataques do residente frente ao intruso. Camundongos Suíços foram mantidos isolados por 10 dias. Os animais receberam uma injeção de veículo ou AM251 (60 min antes do teste) e o número total de ataques em direção ao intruso foi avaliado durante 20 min. Dados apresentados como Média 士 E.P.M., $n=5-7$ animais/grupo. $p>0,05$ em relação ao grupo veículo, obtido pelo teste ANOVA de uma via.

O tempo total de ataques também não sofreu alteração frente à administração de AM251 [Fig. $15\left(F_{4,24}=0,427 ; p=0,788 ;\right.$ ANOVA de uma via)].

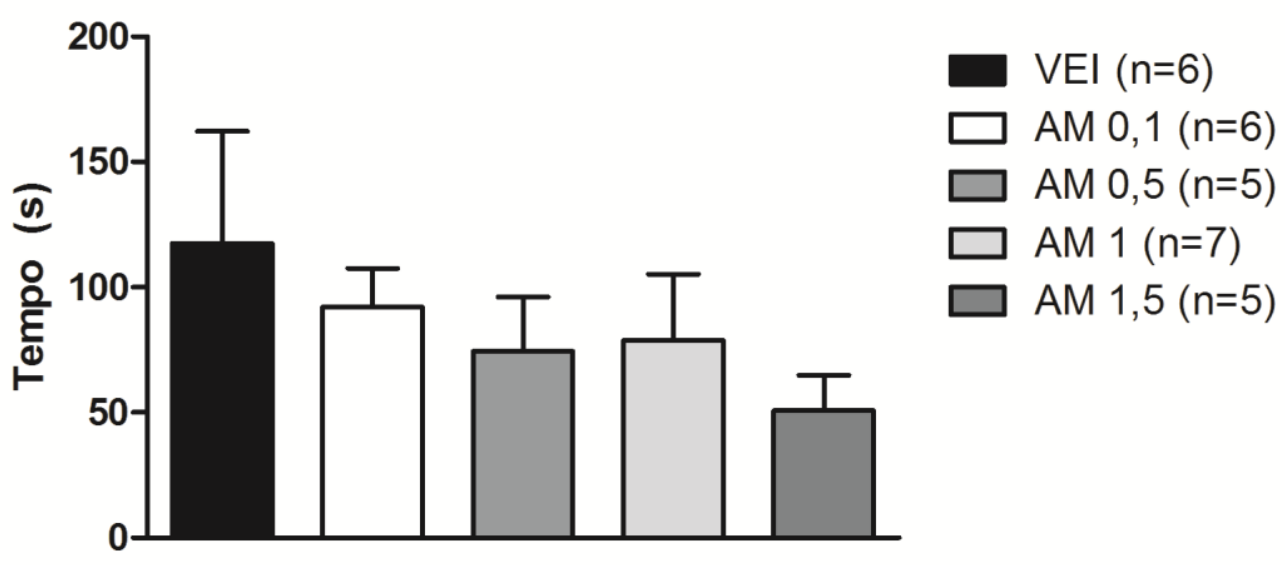

Figura 15. O AM251 não altera o tempo total de ataques do residente frente ao intruso. Camundongos Suíços foram mantidos isolados por 10 dias. Os animais receberam uma injeção de veículo ou AM251 (60 min antes do teste) e o tempo total de ataques (em segundos) direcionado ao intruso foi avaliado durante 20 min. Dados apresentados como Média \pm E.P.M., $n=5-7$ animais/grupo. $p>0,05$ em relação ao grupo veículo, obtido pelo teste ANOVA de uma via. 


\subsection{Efeitos do AM251 sobre a atividade locomotora no teste do campo} aberto

A injeção de AM251, 60 minutos antes do teste, não induziu quaisquer alterações locomotoras nos parâmetros avaliados: Distância Total Percorrida (m) [Fig. 16A $\left(\mathrm{F}_{4,21}=0,16 ; \mathrm{p}=0,957 ;\right.$ ANOVA de uma via)] e Atividade Total ( $\mathrm{n}^{-}$de interrupções) [Fig. 16B ( $F_{4,21}=0,60 ; p=0,664 ; A N O V A$ de uma via)].

A.

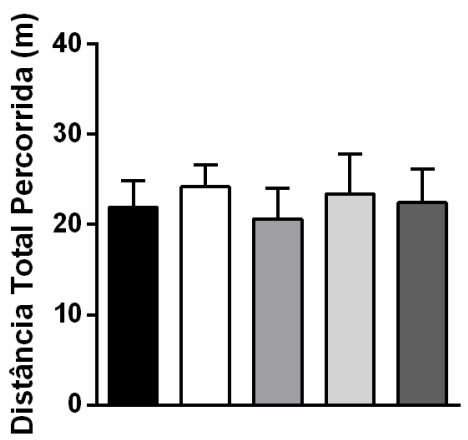

B.

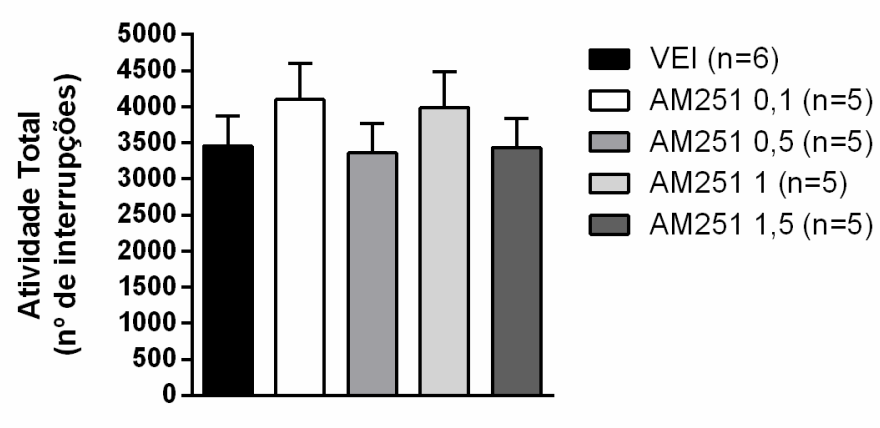

Figura 16. O AM251 não possui efeitos sobre atividade locomotora. Camundongos Suíços foram mantidos isolados por 10 dias. Os animais receberam uma injeção de veículo ou AM251 (60 min antes do teste) e foram submetidos ao teste do campo aberto por 5 min para avaliação da atividade locomotora. A. Distância total percorrida (em metros) pelo animal na arena durante o teste; B. Número de interrupções do infravermelho pelo animal durante $o$ teste. Dados apresentados como Média \pm E.P.M., $n=5-6$ animais/grupo. $p>0,05$ em relação ao grupo veículo, obtido pelo teste ANOVA de uma via. 


\subsection{Efeitos do pré-tratamento com AM251 no efeito anti-agressivo do CBD}

De modo semelhante ao WAY100635, a administração prévia de AM251 foi capaz de bloquear ou atenuar os efeitos anti-agressivos do CBD. Esse resultado evidencia que, além do envolvimento dos receptores 5-HT1A, há a participação dos receptores $\mathrm{CB} 1$ nos mecanismos pelos quais esse fitocanabinoide exerce seus efeitos.

Houve tendência estatística para interação entre as injeções $\left(F_{1,22}=3,96\right.$; $\mathrm{p}=0,059)$. O CBD $(15 \mathrm{mg} / \mathrm{kg})$ foi efetivo em aumentar a latência da primeira mordida e este efeito foi bloqueado pela administração prévia de AM251 (1 mg/kg) [Fig. 17 $\left(F_{3,22}=3,58 ; p=0,030 ;\right.$ ANOVA de uma via seguida pelo pós-teste de Duncan)].

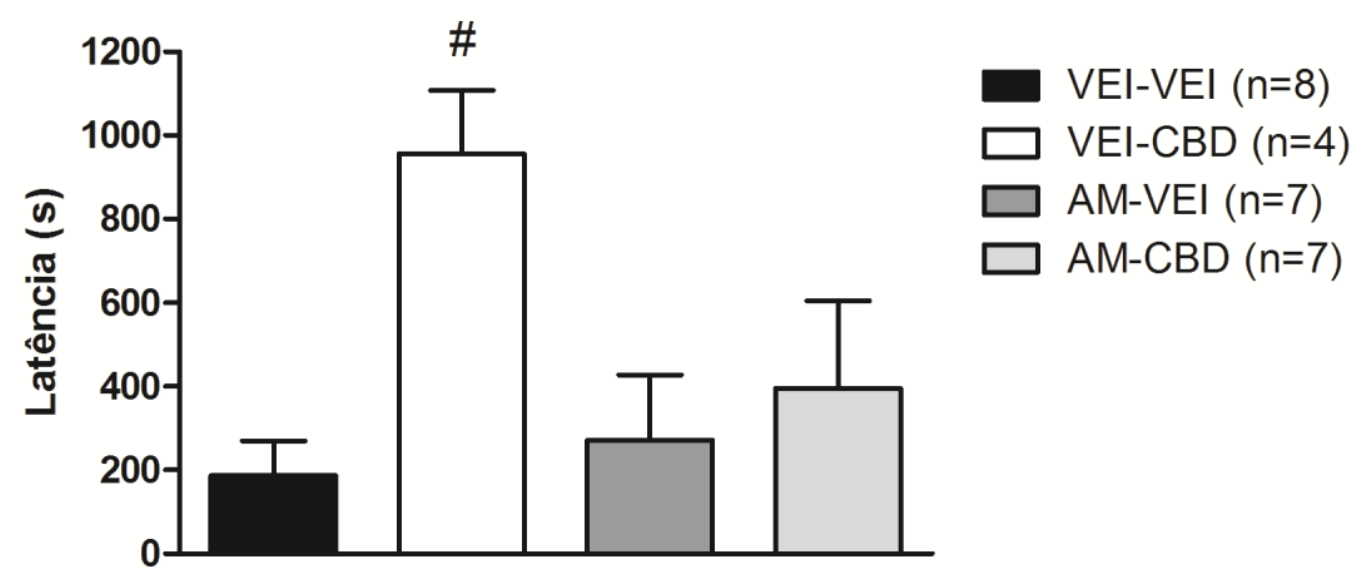

Figura 17. O AM251 bloqueia o efeito do CBD sobre a latência da primeira mordida. Camundongos Suíços foram mantidos isolados por 10 dias. Os animais receberam uma injeção de veículo ou AM251 (1 mg/kg; $60 \mathrm{~min}$ antes do teste) e, posteriormente, uma injeção de veículo ou CBD (15 mg/kg; $30 \mathrm{~min}$ antes do teste) e a latência (tempo em segundos) para primeira mordida em direção ao intruso foi avaliada durante 20 min. Dados apresentados como Média \pm E.P.M., $n=4-8$ animais/grupo. ${ }^{*} p<0,05$ em relação aos grupos veículo-veículo, AM-veículo e AM-canabidiol, obtido pelo teste ANOVA de uma via seguida pelo pós-teste de Duncan. 
A ANOVA mostrou efeito significativo da segunda injeção (CBD ou VEH $\left.F_{1,22}=9,33, p=0,006\right)$. O CBD (15 mg/kg) foi capaz de reduzir o número de ataques e este efeito foi atenuado pelo pré-tratamento com o AM251 (1 mg/kg) [Fig. 18 $\left(F_{3,22}=3,64 ; p=0,028 ; A N O V A\right.$ de uma via seguida pelo pós-teste de Duncan)].

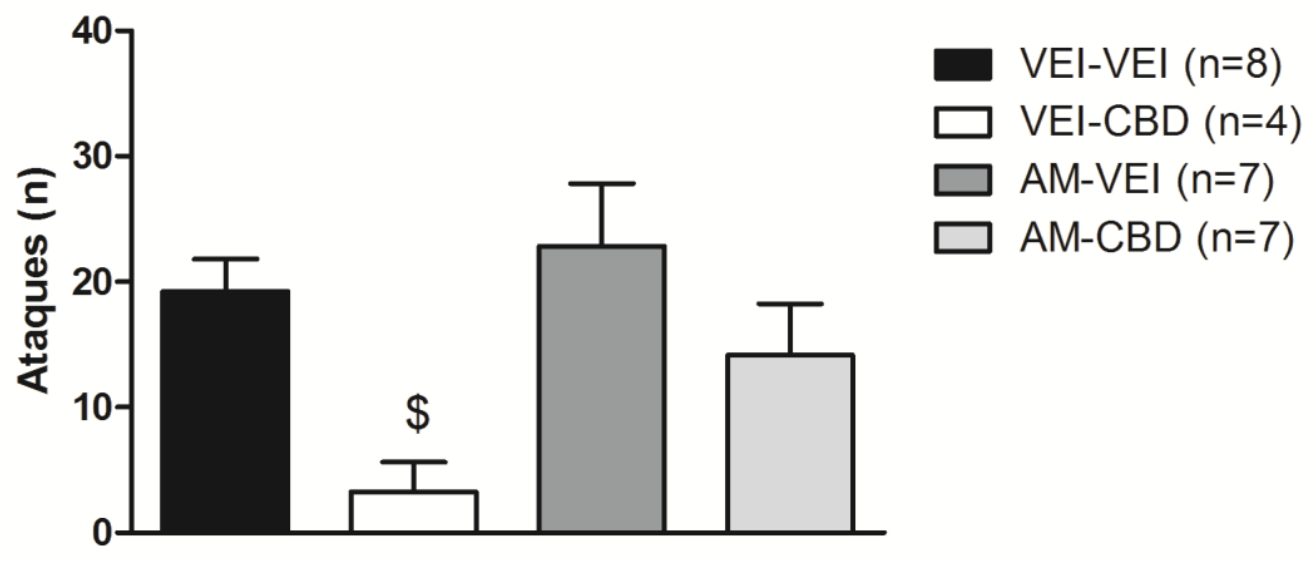

Figura 18. O AM251 atenua o efeito do CBD no número total de ataques do residente frente ao intruso. Camundongos Suíços foram mantidos isolados por 10 dias. Os animais receberam uma injeção de veículo ou AM251 (1 mg/kg; 60 min antes do teste) e, posteriormente, uma injeção de veículo ou CBD (15 mg/kg; $30 \mathrm{~min}$ antes do teste) e o número total de ataques em direção ao intruso foi avaliado durante $20 \mathrm{~min}$. Dados apresentados como Média \pm E.P.M., $\mathrm{n}=4-8$ animais/grupo. ${ }^{\$} \mathrm{p}<0,05$ em relação ao grupo veículo-veículo e AM-veículo, obtido pelo pós-teste de Duncan.

Por fim, o CBD também foi efetivo em diminuir o tempo total de ataques [Fig. $19\left(X^{2}=7,48 ; g . l=3 ; p=0,049 ;\right.$ Kruskal-Wallis $\left.)\right]$. Este efeito foi atenuado pelo prétratamento com AM251 (Mann-Whitney, $p<0,05$ ). 


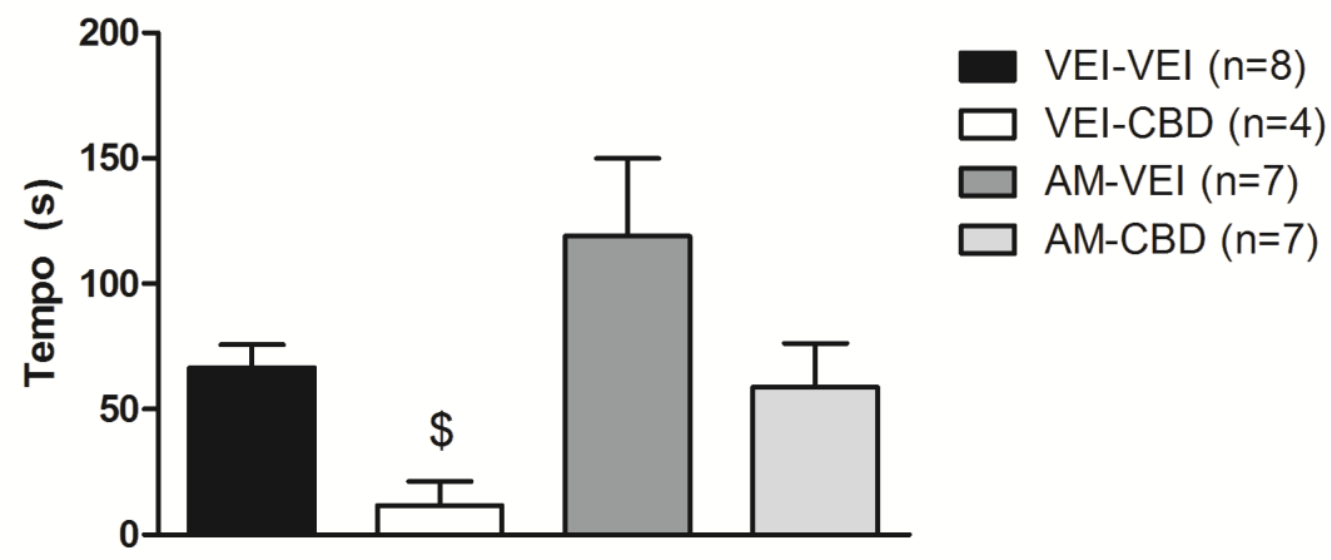

Figura 19. O AM251 atenua o efeito do CBD no tempo total de ataques do residente frente ao intruso. Camundongos Suíços foram mantidos isolados por 10 dias. Os animais receberam uma injeção de veículo ou AM251 (1 mg/kg; $60 \mathrm{~min}$ antes do teste) e, posteriormente, uma injeção de veículo ou CBD (15 mg/kg; $30 \mathrm{~min}$ antes do teste) e o tempo total de ataques (em segundos) direcionado ao intruso foi avaliado durante 20 min. Dados apresentados como Média \pm E.P.M., $n=4-8$ animais/grupo. ${ }^{\$} \mathrm{p}<0,05$ em relação ao grupo veículo-veículo e AM-veículo, obtido pelo teste de Kruskal Wallis. 
Discussão 


\section{DISCUSSÃO}

O presente estudo mostrou que o CBD é capaz de atenuar as consequências comportamentais no modelo de agressão induzida por isolamento social em camundongos e que esse efeito envolve os receptores do tipo 5-HT1A e CB1.

Como discutido brevemente na Introdução, diversos estudos têm identificado a 5-HT como o principal modulador de comportamentos impulsivos e agressivos em inúmeras espécies, de modo que a neurotransmissão serotoninérgica tem sido considerada essencial no controle de comportamentos defensivos (DE BOER; KOOLHAAS, 2005; TAKAHASHI et al., 2011). Essa hipótese é baseada em evidências pré-clínicas nas quais a administração de drogas que diminuem a sinalização serotoninérgica, através da inibição de síntese (paraclorofenilalanina, PCPA) ou morte de neurônios 5-HT (5,7 dihidroxitriptamina, 5,7-DHT), induzem comportamentos agressivos em animais (OLIVIER, 2015). Além disso, evidências clínicas fortaleceram essa ideia, uma vez que pacientes psiquiátricos e vítimas de suicídio apresentavam baixas concentrações de metabólitos serotoninérgicos no líquido cefalorraquidiano (BROWN et al., 1982; BROWN et al., 1979; LINNOILA et al., 1983; VIRKKUNEN et al., 1994). De mesmo modo, já foi sugerida essa associação entre metabólitos serotoninérgicos e comportamentos tipo-agressivos em inúmeras espécies de animais, como macacos (MEHLMAN et al., 1994), camundongos (CARAMASCHI; DE BOER; KOOLHAAS, 2007) e peixes (CLOTFELTER et al., 2007). Além disso, foi observado que a depleção de triptofano (precursor essencial de 5-HT) em primatas (CHAMBERLAIN et al., 1987) e humanos (BJORK et al., 1999), a inibição da síntese de 5-HT em ratos (VERGNES; DEPAULIS; BOEHRER, 1986), a hiper-expressão de receptores 5-HT1A nos núcleos da rafe (AUDERO et al., 2013), bem como a deleção gênica da triptofano 
hidroxilase (enzima-chave para síntese de 5-HT) (MOSIENKO et al., 2012), em camundongos, favorecem a agressividade. Por outro lado, a administração sistêmica de triptofano diminui comportamentos agressivos em camundongos submetidos ao teste do residente-intruso (WALZ et al., 2013) e em pacientes com esquizofrenia (MORAND; YOUNG; ERVIN, 1983). De mesmo modo, a administração de inibidores seletivos da recaptação ou das enzimas metabolizadoras de serotonina também diminuem esses comportamentos em camundongos (MICZEK; BARROS; et al., 1998; MICZEK et al., 1994; MICZEK et al., 1995).

Audero e colaboradores (2013) demonstraram que tanto a redução aguda quanto crônica da atividade de neurônios 5-HT de camundongos adultos está associada ao aumento da agressão, sem quaisquer alterações em modelos animais de ansiedade ou de interação social. Neste trabalho, os animais que superexpressavam os autorreceptores inibitórios do tipo 5-HT1A, localizados nos corpos celulares de neurônios serotoninérgios dos núcleos da rafe, apresentaram comportamentos pró-agressivos (menor latência para início dos ataques e maior número de ataques contra os intrusos) - provavelmente devido à diminuição da atividade destes neurônios. Já animais geneticamente manipulados que expressavam receptores 5-HT1A exclusivamente pré-sinápticos, ou seja, em neurônios serotoninérgicos, e que tiveram a inibição da atividade neuronal serotoninérgica realizada de forma aguda através da administração de 8-OH-DPAT, um agonista de receptores 5-HT1A, apresentaram também aumento no número de ataques. A partir disso, considerando que corpos celulares de neurônios serotoninérgicos localizam-se principalmente nos núcleos dorsal e mediano da rafe (AZMITIA; SEGAL, 1978; PARENT; DESCARRIES; BEAUDET, 1981), pode-se hipotetizar que a redução do disparo destes neurônios, pode levar à redução nos 
níveis extracelulares de 5-HT em áreas de projeção ascendentes envolvidas no controle de comportamentos agressivos, como o córtex pré-frontal (CPF) (NELSON, R. J.; TRAINOR, 2007). Ainda nesse sentido, Van Erp e Miczek (2000) observaram que ratos possuem redução dos níveis extracelulares de 5-HT no CPF durante os comportamentos agressivos e que essa diminuição perdura por mais de 1 hora após o término do teste, sem quaisquer alterações nesse sistema de neurotransmissão no núcleo accumbens.

Além das evidências da manipulação experimental do sistema serotoninérgico, a neurocircuitaria deste sistema também permite sugeri-lo como um importante neurotransmissor envolvido em comportamentos defensivos visto que os corpos celulares de neurônios serotoninérgicos, localizados nos núcleos da rafe, se projetam para diversas regiões cerebrais envolvidas na agressão, como o estriado, amígdala, hipocampo, hipotálamo e córtex pré-frontal (AZMITIA; SEGAL, 1978; PARENT et al., 1981; STEINBUSCH, 1981).

Acredita-se que dois subtipos de receptores pelos quais a 5-HT atua estejam particularmente envolvidos em comportamentos agressivos, são eles os 5-HT1A e 5HT1B (TAKAHASHI et al., 2011). Ambos são acoplados à proteína $G$ inibitória $\left(G_{i / 0}\right)$ e agem inibindo a adenilato ciclase e canais de cálcio voltagem-dependentes, bem como ativando os canais retificadores de entrada de potássio sensíveis à proteína $G$ (GIRK) - levando, portanto, à hiperpolarização celular e inibição da liberação de transmissores (SANDERS-BUSH; HAZELWOOD, 2012). Os receptores 5-HT1A são encontrados nos corpos celulares de neurônios serotoninérgicos nos núcleos da rafe - onde atuam como autorreceptores somatodendríticos inibitórios - e em outras regiões (hipocampo, amígdala, septo lateral, córtex, tálamo, gânglios da base), onde 
atuam como heteroreceptores pós-sinápticos inibitórios. Já o subtipo 5-HT1D/1B é abundantemente expresso na substância nigra e nos núcleos da base, especialmente no globo pálido, onde atua como autorreceptor pré-sináptico inibitório; ou seja, está localizado em terminações axônicas e inibe a liberação de 5-HT. Porém, também pode ser um heteroreceptor, estando expresso em terminais axônicos de células pós-sinápticas não serotoninérgicas (OLIVIER, 2004; SANDERS-BUSH; HAZELWOOD, 2012). Portanto, a ativação pré-sináptica de ambos os subtipos do receptor culmina na diminuição da sinalização serotoninérgica, enquanto que a ativação pós-sináptica altera outros sistemas neurotransmissores.

A relação linear entre diminuição da sinalização serotoninérgica e/ou do disparo de neurônios 5-HT e o aumento nos níveis de comportamentos agressivos perdeu força quando estudos pré-clínicos, baseados na administração central (DE ALMEIDA; LUCION, 1997; MOS et al., 1993) ou sistêmica (CARAMASCHI et al., 2007; DE BOER et al., 2000; MICZEK; HUSSAIN; et al., 1998) de agonistas de receptores 5-HT1A e 5-HT1B, verificaram efeitos antiagressivos (DE BOER; KOOLHAAS, 2005). Portanto, esses resultados permitem sugerir a possibilidade da existência de mecanismos mais complexos, como vias auto-regulatórias ou da ação do sistema serotoninérgico sobre outros sistemas neurotransmissores.

Já foi demonstrado que a administração aguda de agonistas 5-HT1A diminui comportamentos agressivos em inúmeras espécies - camundongos, ratos, peixes, anfíbios, aves e primatas (TOMPKINS et al., 1980; LINDGREN; KANTAK, 1987; MCMILLEN et al., 1988; BELL; HOBSON, 1994; BLANCHARD et al., 1988; CLOTFELTER et al., 2007; DE BOER; KOOLHAAS, 2005; DE BOER et al., 
1999;2000; JOPPA; ROWE; MEISEL, 1997; MICZEK; HUSSAIN; et al., 1998; MUEHLENKAMP; LUCION; VOGEL, 1995; SANCHEZ et al., 1993; SPERRY; THOMPSON; WINGFIELD, 2003; TEN EYCK, 2008) e que a administração prévia de WAY100635 (antagonista dos receptores 5-HT1A) é capaz de bloquear esse efeito anti-agressivo (DE BOER et al., 2000). Corroborando esses resultados, a microinjeção de agonista dos receptores 5-HT1A no córtex pré-frontal órbito-ventral de camundongos diminui comportamentos agressivos e este efeito é bloqueado pela administração prévia de WAY100635 (STEIN et al., 2013). Porém, muitos desses efeitos anti-agressivos observados a partir da administração de agonistas dos receptores 5-HT1A são decorrentes de efeitos sedativos, atividade locomotora diminuída, estereotipias e redução de interesse social (DE BOER; KOOLHAAS, 2005; MICZEK; HUSSAIN; et al., 1998; TAKAHASHI et al., 2011). De modo semelhante aos agonistas de receptores 5-HT1A, a administração sistêmica aguda de agonistas dos receptores 5-HT1B em ratos e camundongos foi capaz de reduzir comportamentos agressivos sem comprometimento motor e/ou sensorial (DE ALMEIDA; MICZEK, 2002; DE BOER; KOOLHAAS, 2005; FISH; FACCIDOMO; MICZEK, 1999; MICZEK et al., 2002) e esses efeitos foram bloqueados pela administração de GR127935 (antagonista 5-HT1B/1D) (DE BOER; KOOLHAAS, 2005).

Assim como os inúmeros trabalhos da literatura que descrevem efeitos antiagressivos a partir da administração de agonistas dos receptores 5 -HT1A, o presente estudo evidenciou que há o envolvimento deste subtipo de receptor nas ações comportamentais do CBD, uma vez que a administração de WAY100635 foi capaz de bloquear ou atenuar os efeitos anti-agressivos deste composto. Vale a pena ressaltar que os efeitos observados com esse fitocanabinoide foram 
desprovidos de alterações locomotoras frequentemente observadas com agonistas 5-HT1A. Os efeitos antiagressivos encontrados neste trabalho corroboram estudos do nosso e de outros grupos de pesquisa, nos quais os efeitos agudos ansiolíticos e anti-estresse do CBD envolvem a ativação de receptores $5-\mathrm{HT} 1 \mathrm{~A}$ em roedores (CAMPOS et al., 2013; CAMPOS; FERREIRA; et al., 2012; CAMPOS; GUIMARAES, 2008; FOGACA et al., 2014; GOMES et al., 2012; GOMES; RESSTEL; GUIMARAES, 2011; RESSTEL et al., 2006; RESSTEL et al., 2009; SOARES VDE et al., 2010; TWARDOWSCHY et al., 2013; ZANELATI et al., 2010).

Entretanto, as regiões envolvidas e os mecanismos pelos quais agonistas dos recetores 5-HT1A e 5-HT1B exercem suas ações antiagressivas ainda são pouco conhecidos, embora algumas hipóteses tenham sido propostas. No caso de tratamentos repetidos, sugere-se que a constante ativação dos autorreceptores inibitórios leve a mecanismos de dessensibilização que, por sua vez, poderão culminar na perda do autocontrole inibitório e, consequentemente, no aumento do disparo de neurônios serotoninérgicos e maior liberação de 5-HT em regiões alvo (AUDERO et al., 2013; OLIVIER, 2015; TAKAHASHI et al., 2011). Já no âmbito de administração aguda, alguns trabalhos sugerem que os efeitos desses agonistas ocorrem através de suas ações sobre os autorreceptores ou receptores présinápticos, culminando em uma redução da atividade de neurônios serotoninérgicos e, consequentemente, da liberação de 5-HT em áreas de projeção (AUDERO et al., 2013; TAKAHASHI et al., 2011). Entretanto, esta hipótese perdeu força com achados de que a administração de PCPA ou 5,7-DHT não afetam os efeitos antiagressivos dos agonistas de receptores 5-HT1A e 5-HT1B (DE ALMEIDA; MICZEK, 2002; MICZEK; HUSSAIN; et al., 1998; SANCHEZ; HYTTEL, 1994; SIJBESMA et al., 1991). Então, a partir desses trabalhos que observaram que 
a depleção de 5-HT ou lesão em neurônios serotoninérgicos não altera as ações dos agonistas, começou a ser sugerida uma maior seletividade de ação dessas drogas sobre heterorreceptores ou receptores pós-sinápticos, ou seja, uma atividade modulatória da neurotransmissão serotoninérgica sobre outros sistemas que também possuem papel importante sobre comportamentos agressivos. Sabe-se, por exemplo, que receptores 5-HT1A também são expressos em neurônios GABAérgicos presentes na rafe (BONNAVION et al., 2010; KIRBY et al., 2003; MARINELLI et al., 2004), portanto a inibição simultânea de ambos os sistemas (5-HT e GABA) poderia mediar esses efeitos. Além disso, inúmeros trabalhos da literatura evidenciam a influência de receptores serotoninérgicos inibitórios sobre a atividade de neurônios glutamatérgicos e GABAérgicos em diversas regiões cerebrais, como CPF e hipocampo, dentre outras (ALBERT; VAHID-ANSARI; LUCKHART, 2014; CIRANNA, 2006). Considerando que a 5-HT através de seus receptores inibitórios do tipo 5-HT1A pode modular a atividade de ambos os sistemas citados anteriormente e que estes, por sua vez, desempenham papéis relevantes em respostas comportamentais relacionadas à agressão, esse pode ser um provável mecanismo pelo qual o CBD exerce seus efeitos antiagressivos via receptores 5HT1A. Desse modo, futuros experimentos serão realizados para testar esta hipótese.

Nos últimos anos, o sistema endocanabinoide tem ganhado destaque em estudos relacionados ao estresse, sendo atualmente considerado um dos principais sistemas envolvidos na modulação de respostas comportamentais frente a estímulos estressores (HARING; GUGGENHUBER; LUTZ, 2012). Os receptores CB1 estão localizados na membrana plasmática das terminações nervosas pré-sinápticas e amplamente distribuídos no encéfalo, concentrando-se no hipocampo, cerebelo, 
hipotálamo, substância negra, córtex, vias dopaminérgicas mesolímbicas e em áreas de associação do córtex cerebral (HERKENHAM et al., 1990; MACKIE, 2005; RANG et al., 2011). Assim como os receptores 5-HT1A, os receptores CB1 são acoplados à proteína $\mathrm{G}$ inibitória $\left(\mathrm{G}_{\mathrm{i} / \mathrm{o}}\right)$ inibindo, portanto, a liberação de neurotransmissores (RANG et al., 2011). Diante da descoberta de receptores canabinoides específicos, os mediadores endógenos também foram evidenciados (RANG et al., 2011; O'BRIEN, 2012). A anandamida ( $N$-araquidoniletanolamida) e o 2-araquidonoil glicerol (2-AG) são os dois endocanabinoides mais bem caracterizados, produzidos sob-demanda (através da clivagem de fosfolipídios de membrana dos neurônios pós-sinápticos) e agindo como mensageiros retrógrados em sinapses centrais (MECHOULAM; PARKER, 2013; WILSON; NICOLL, 2002). O término de seus efeitos se dá a partir da internalização neuronal seguida de hidrólise (MARCO et al., 2011; MOREIRA et al., 2009). Nesse sentido, a modulação do sistema canabinoide tem sido alvo de interesse para o entendimento desse sistema frente a situações aversivas, visto que o controle retrógrado dos endocanabinoides modula a liberação de diversos neurotransmissores (monoaminas, colecistocinina, glutamato e GABA) envolvidos em respostas comportamentais (ASO et al., 2009; JUNG et al., 2005; MATO et al., 2007; MELIS et al., 2004).

Inúmeros estudos têm demonstrado que canabinoides desempenham um perfil bifásico dose-dependente em roedores, de modo que baixas doses produzem respostas tipo-ansiolíticas, enquanto que altas doses perdem esses efeitos (BATISTA; FOGACA; GUIMARAES, 2015; CAMPOS; GUIMARAES, 2009; CASAROTTO et al., 2012; FOGACA et al., 2012; FOGACA et al., 2013; MOREIRA; AGUIAR; GUIMARAES, 2007; RUBINO et al., 2008; VIVEROS; MARCO; FILE, 
2005). Porém, estudos sobre o envolvimento desse sistema na agressão continuam escassos. Alguns trabalhos já analisaram os efeitos do CBD sobre comportamentos agressivos em roedores, porém não encontraram efeitos significativos com a droga (HAM; DE JONG, 1975; VAN REE; NIESINK; NIR, 1984). No primeiro trabalho, camundongos Suíços, isolados de contato visual e tátil por 6 semanas, receberam 1 injeção aguda de CBD (20 ou $40 \mathrm{mg} / \mathrm{kg}$ ) e foram colocados em uma gaiola de alumínio com outro animal isolado durante $5 \mathrm{~min}, 1,2$ e 4 h após a administração. No referido trabalho falta uma descrição detalhada dos procedimentos metodológicos para melhor compreensão dos resultados, como por exemplo, se apenas 1 animal isolado recebeu a droga ou ambos - o que, a nosso ver, dificulta possíveis comparações com os nossos resultados. Além disso, vale a pena ressaltar que o modelo animal e o tempo de análise após a administração da droga são diferentes dos utilizados no presente trabalho. Já no segundo trabalho, ratos Wistar foram mantidos isolados por 7 dias, receberam 1 injeção de CBD (2 ou 20 mg/kg) e então foram submetidos ao teste do residente-intruso (os animais intrusos eram mantidos agrupados). Novamente, o CBD não foi efetivo em reduzir comportamentos agressivos. Acreditamos que a divergência de resultados entre o referido trabalho e o nosso pode ser em decorrência de variações metodológicas bem como das espécies utilizadas.

No que concerne ao papel dos receptores CB1 em respostas defensivas, já foi evidenciado que animais com deleção gênica (animais knockout) para estes receptores são mais agressivos quando comparados a animais selvagens (MARTIN et al., 2002; RODRIGUEZ-ARIAS et al., 2013). Os camundongos geneticamente modificados despenderam mais tempo em comportamentos de ataque e ameaça, apresentaram uma menor latência para o primeiro encontro agressivo, maiores 
índices de impulsividade e maior interação agressiva durante testes de interação social. Ainda nesse sentido, foi observado que a administração de agonista CB1 foi capaz de reduzir consideravelmente comportamentos agressivos em animais sem a deleção. Além disso, conforme mencionado na Introdução, os animais CB1 knockout possuem maiores níveis de RNAm para COMT nos núcleos dorsal e medial da rafe, bem como na amígdala, enquanto a enzima MAO-A também está aumentada apenas nessa última estrutura. Estes dados sugerem que aumento na expressão de enzimas metabolizadoras nos animais pode reduzir os níveis de monoaminas, incluindo a 5-HT, e aumentar comportamentos agressivos (MARTIN et al., 2002; RODRIGUEZ-ARIAS et al., 2013). Desse modo, pode-se propor que receptores CB1 desempenhem um importante papel no controle da agressão.

Além da influência do sistema canabinoide sobre a neurotransmissão 5-HT, deve-se considerar a modulação deste - através de receptores CB1 - sobre outros sistemas neurotransmissores importantes no controle de respostas comportamentais, inclusive agressão. Recentemente, Rey e colaboradores (2012) descreveram um possível mecanismo pelo qual agonistas dos receptores CB1 podem exercer seus efeitos bifásicos sobre comportamentos relacionados à ansiedade, através do uso de animais knockout para receptores CB1 em neurônios glutamatérgicos corticais ou neurônios GABAérgicos prosencefálicos . Os referidos autores postulam que a ativação de receptores CB1 em neurônios glutamatérgicos medeia os efeitos tipo-ansiolíticos observados com baixas doses do agonista, enquanto que altas doses da droga induz seus efeitos ansiogênicos por ativação de receptores CB1 em neurônios GABAérgicos. Desse modo, não se pode descartar que os efeitos do CBD sobre comportamentos agressivos se deem a partir de vários sistemas de neurotransmissão de modo dose-dependente. Apesar de possuir baixa 
ou nenhuma atividade sobre receptores $C B 1$, vale a pena relembrar que o $C B D$ pode induzir seus efeitos por mecanismos indiretos através da inibição da FAAH (BISOGNO et al., 2001), com consequente aumento nos níveis de AEA que, por sua vez, atuaria diretamente sobre os receptores CB1. Portanto, esse e outros trabalhos da literatura evidenciam que, devido a sua ampla distribuição cerebral, os receptores CB1 podem modular diversos sistemas neurotransmissores simultaneamente de modo que a concentração de seus agonistas pode influenciar o seu sistema-alvo de ação. Então, a partir da presente discussão, pode-se sugerir que o CBD induza seus efeitos antiagressivos por modular diferentes sistemas de neurotransmissão tanto via 5-HT1A quanto via CB1.

Até o presente momento não temos conhecimento de trabalhos na literatura que tenham observado mecanismo de ação misto - via receptores 5-HT1A e CB1 para os efeitos do CBD envolvendo respostas comportamentais agudas, como no presente trabalho. Entretanto, já foi evidenciado um mecanismo de ação misto envolvendo receptores 5-HT1A e CB2 - para os efeitos neuroprotetores do CBD em um modelo de hipóxia-isquêmica em porcos (PAZOS et al., 2013).

Desse modo, considerando que o CBD pode induzir seus efeitos por ação direta sobre os receptores 5-HT1A ou por sua influência sobre o sistema ECB, através da inibição da FAAH e consequente aumento dos níveis de AEA, acreditamos que ambos os mecanismos (direto ou indireto) podem estar envolvidos nas respostas comportamentais antiagressivas obtidas a partir da administração aguda do CBD. Entretanto, mais estudos são necessários para tentar elucidar a localização e o mecanismo pelos quais receptores CB1 e 5-HT1A mediariam os efeitos antiagressivos do CBD. 
Conclusão 


\section{CONCLUSÃO}

O CBD tem se mostrado efetivo em situações de estresse e uma alternativa terapêutica para tratamento de alguns transtornos neuropsiquiátricos. Contribuindo com estes estudos, o presente trabalho indica que esse fitocanabinoide também pode possuir atividade anti-agressiva. O mecanismo envolvido nesse efeito ainda não é claro, mas nossos resultados sugerem o envolvimento de receptores $5-\mathrm{HT} 1 \mathrm{~A}$ e CB1.

Caso estes efeitos sejam confirmados em novos estudos pré-clínicos e clínicos, o CBD poderia ser uma futura opção terapêutica para tratar comportamentos agressivos. 
Referências 


\section{REFERÊNCIAS BIBLIOGRÁFICAS}

AHRENS, J. et al. The nonpsychotropic cannabinoid cannabidiol modulates and directly activates alpha-1 and alpha-1-Beta glycine receptor function. Pharmacology, v. 83, n. 4, p. 217-22, 2009.

ALBERT, P. R.; VAHID-ANSARI, F.; LUCKHART, C. Serotonin-prefrontal cortical circuitry in anxiety and depression phenotypes: pivotal role of pre- and post-synaptic 5-HT1A receptor expression. Front Behav Neurosci, v. 8, p. 199, 2014.

ARCHER, J. The nature of human aggression. Int J Law Psychiatry, v. 32, n. 4, p. 202-8, Jul-Aug 2009.

ASO, E. et al. Lack of CB1 receptor activity impairs serotonergic negative feedback. J Neurochem, v. 109, n. 3, p. 935-44, May 2009.

Associação Americana de Psiquiatria - APA (2013). Manual diagnóstico e estatístico de doenças mentais, $5^{\mathrm{a}}$ ed. Associação americana de Psiquiatria, Washington, DC.

AUDERO, E. et al. Suppression of serotonin neuron firing increases aggression in mice. $\mathbf{J}$ Neurosci, v. 33, n. 20, p. 8678-88, May 152013.

AZMITIA, E. C.; SEGAL, M. An autoradiographic analysis of the differential ascending projections of the dorsal and median raphe nuclei in the rat. J Comp Neurol, v. 179, n. 3, p. 641-67, Jun 11978.

BATISTA, P. A.; FOGACA, M. V.; GUIMARAES, F. S. The endocannabinoid, endovanilloid and nitrergic systems could interact in the rat dorsolateral periaqueductal gray matter to control anxiety-like behaviors. Behav Brain Res, v. 293, p. 182-8, Oct 152015.

BELL, R.; HOBSON, H. 5-HT1A receptor influences on rodent social and agonistic behavior: a review and empirical study. Neurosci Biobehav Rev, v. 18, n. 3, p. 325-38, Fall 1994.

BERGAMASCHI, M. M. et al. Cannabidiol reduces the anxiety induced by simulated public speaking in treatment-naive social phobia patients. Neuropsychopharmacology, v. 36, n. 6 , p. 1219-26, May 2011.

BERKOWITZ, L. Agression. Its causes, consequences and control. Nova lorque: Mc Graw Hill, 1993.

BISOGNO, T. et al. Molecular targets for cannabidiol and its synthetic analogues: effect on vanilloid VR1 receptors and on the cellular uptake and enzymatic hydrolysis of anandamide. Br J Pharmacol, v. 134, n. 4, p. 845-52, Oct 2001.

BJORK, J. M. et al. The effects of tryptophan depletion and loading on laboratory aggression in men: time course and a food-restricted control. Psychopharmacology (Berl), v. 142, n. 1, p. 24-30, Feb 1999. 
BLANCHARD, D. C. et al. 'Taming' of wild rats (Rattus rattus) by $5 \mathrm{HT} 1 \mathrm{~A}$ agonists buspirone and gepirone. Pharmacol Biochem Behav, v. 31, n. 2, p. 269-78, Oct 1988.

BONNAVION, $\mathrm{P}$. et al. Heterogeneous distribution of the serotonin $5-\mathrm{HT}(1 \mathrm{~A})$ receptor mRNA in chemically identified neurons of the mouse rostral brainstem: Implications for the role of serotonin in the regulation of wakefulness and REM sleep. J Comp Neurol, v. 518, n. 14, p. 2744-70, Jul 152010.

BRAIN, P. What does individual housing mean to a mouse? Life Sci, v. 16, n. 2, p. 187-200, Jan 151975.

BROWN, G. L. et al. Aggression, suicide, and serotonin: relationships to CSF amine metabolites. Am J Psychiatry, v. 139, n. 6, p. 741-6, Jun 1982.

BROWN, G. L. et al. Aggression in humans correlates with cerebrospinal fluid amine metabolites. Psychiatry Res, v. 1, n. 2, p. 131-9, Oct 1979.

BRUNNER, D.; HEN, R. Insights into the neurobiology of impulsive behavior from serotonin receptor knockout mice. Ann N Y Acad Sci, v. 836, p. 81-105, Dec 291997.

CAMPOS, A. C. et al. Involvement of serotonin-mediated neurotransmission in the dorsal periaqueductal gray matter on cannabidiol chronic effects in panic-like responses in rats. Psychopharmacology (Berl), v. 226, n. 1, p. 13-24, Mar 2013.

CAMPOS, A. C.; FERREIRA, F. R.; GUIMARAES, F. S. Cannabidiol blocks long-lasting behavioral consequences of predator threat stress: possible involvement of $5 \mathrm{HT} 1 \mathrm{~A}$ receptors. J Psychiatr Res, v. 46, n. 11, p. 1501-10, Nov 2012.

CAMPOS, A. C.; GUIMARAES, F. S. Involvement of $5 \mathrm{HT} 1 \mathrm{~A}$ receptors in the anxiolytic-like effects of cannabidiol injected into the dorsolateral periaqueductal gray of rats. Psychopharmacology (Berl), v. 199, n. 2, p. 223-30, Aug 2008.

CAMPOS, A. C.; GUIMARAES, F. S. Evidence for a potential role for TRPV1 receptors in the dorsolateral periaqueductal gray in the attenuation of the anxiolytic effects of cannabinoids. Prog Neuropsychopharmacol Biol Psychiatry, v. 33, n. 8, p. 1517-21, Nov 132009.

CAMPOS, A. C. et al. Multiple mechanisms involved in the large-spectrum therapeutic potential of cannabidiol in psychiatric disorders. Philos Trans R Soc Lond B Biol Sci, v. 367, n. 1607, p. 3364-78, Dec 52012.

CARAMASCHI, D.; DE BOER, S. F.; KOOLHAAS, J. M. Differential role of the 5-HT1A receptor in aggressive and non-aggressive mice: an across-strain comparison. Physiol Behav, v. 90, n. 4, p. 590-601, Mar 162007.

CASAROTTO, P. C. et al. Cannabidiol inhibitory effect on marble-burying behaviour: involvement of CB1 receptors. Behav Pharmacol, v. 21, n. 4, p. 353-8, Jul 2010. 
CASAROTTO, P. C. et al. Opposing roles for cannabinoid receptor type-1 (CB(1)) and transient receptor potential vanilloid type-1 channel (TRPV1) on the modulation of panic-like responses in rats. Neuropsychopharmacology, v. 37, n. 2, p. 478-86, Jan 2012.

CHAMBERLAIN, B. et al. The effect of raising or lowering tryptophan levels on aggression in vervet monkeys. Pharmacol Biochem Behav, v. 28, n. 4, p. 503-10, Dec 1987.

CIRANNA, L. Serotonin as a modulator of glutamate- and GABA-mediated neurotransmission: implications in physiological functions and in pathology. Curr Neuropharmacol, v. 4, n. 2, p. 101-14, Apr 2006.

CLOTFELTER, E. D. et al. Serotonin decreases aggression via 5-HT1A receptors in the fighting fish Betta splendens. Pharmacol Biochem Behav, v. 87, n. 2, p. 222-31, Jun-Jul 2007.

COPPENS, C. M. et al. Impulsivity and aggressive behavior in Roman high and low avoidance rats: baseline differences and adolescent social stress induced changes. Physiol Behav, v. 105, n. 5, p. 1156-60, Mar 202012.

CRIPPA, J. A. et al. Neural basis of anxiolytic effects of cannabidiol (CBD) in generalized social anxiety disorder: a preliminary report. J Psychopharmacol, v. 25, n. 1, p. 121-30, Jan 2011.

DE ALMEIDA, R. M.; CABRAL, J. C.; NARVAES, R. Behavioural, hormonal and neurobiological mechanisms of aggressive behaviour in human and nonhuman primates. Physiol Behav, v. 143, p. 121-35, May 12015.

DE ALMEIDA, R. M.; LUCION, A. B. 8-OH-DPAT in the median raphe, dorsal periaqueductal gray and corticomedial amygdala nucleus decreases, but in the medial septal area it can increase maternal aggressive behavior in rats. Psychopharmacology (Berl), v. 134, n. 4, p. 392-400, Dec 1997.

DE ALMEIDA, R. M.; MICZEK, K. A. Aggression escalated by social instigation or by discontinuation of reinforcement ("frustration") in mice: inhibition by anpirtoline: a 5-HT1B receptor agonist. Neuropsychopharmacology, v. 27, n. 2, p. 171-81, Aug 2002.

DE BOER, S. F.; KOOLHAAS, J. M. 5-HT1A and 5-HT1B receptor agonists and aggression: a pharmacological challenge of the serotonin deficiency hypothesis. Eur $\mathbf{J}$ Pharmacol, $\mathbf{v}$. 526, n. 1-3, p. 125-39, Dec 52005.

DE BOER, S. F. et al. Selective antiaggressive effects of alnespirone in resident-intruder test are mediated via 5-hydroxytryptamine1A receptors: A comparative pharmacological study with 8-hydroxy-2-dipropylaminotetralin, ipsapirone, buspirone, eltoprazine, and WAY100635. J Pharmacol Exp Ther, v. 288, n. 3, p. 1125-33, Mar 1999.

DE BOER, S. F. et al. Somatodendritic 5-HT(1A) autoreceptors mediate the anti-aggressive actions of 5-HT(1A) receptor agonists in rats: an ethopharmacological study with S-15535, alnespirone, and WAY-100635. Neuropsychopharmacology, v. 23, n. 1, p. 20-33, Jul 2000. 
DE PETROCELLIS, L. et al. Plant-derived cannabinoids modulate the activity of transient receptor potential channels of ankyrin type-1 and melastatin type-8. J Pharmacol Exp Ther, v. 325, n. 3, p. 1007-15, Jun 2008.

FARRINGTON, D. P. Early predictors of adolescent aggression and adult violence. Violence Vict, v. 4, n. 2, p. 79-100, Summer 1989.

FERRIS, C. F. et al. Imaging the neural circuitry and chemical control of aggressive motivation. BMC Neurosci, v. 9, p. 111, 2008.

FISH, E. W.; FACCIDOMO, S.; MICZEK, K. A. Aggression heightened by alcohol or social instigation in mice: reduction by the 5-HT(1B) receptor agonist CP-94,253. Psychopharmacology (Berl), v. 146, n. 4, p. 391-9, Oct 1999.

FOGACA, M. V. et al. The endocannabinoid and endovanilloid systems interact in the rat prelimbic medial prefrontal cortex to control anxiety-like behavior. Neuropharmacology, $v$. 63, n. 2, p. 202-10, Aug 2012.

FOGACA, M. V. et al. Effects of glutamate NMDA and TRPV1 receptor antagonists on the biphasic responses to anandamide injected into the dorsolateral periaqueductal grey of Wistar rats. Psychopharmacology (Berl), v. 226, n. 3, p. 579-87, Apr 2013.

FOGACA, M. V. et al. Effects of intra-prelimbic prefrontal cortex injection of cannabidiol on anxiety-like behavior: involvement of $5 \mathrm{HT} 1 \mathrm{~A}$ receptors and previous stressful experience. Eur Neuropsychopharmacol, v. 24, n. 3, p. 410-9, Mar 2014.

GOMES, F. V. et al. Cannabidiol injected into the bed nucleus of the stria terminalis reduces the expression of contextual fear conditioning via 5-HT1A receptors. J Psychopharmacol, v. 26, n. 1, p. 104-13, Jan 2012.

GOMES, F. V.; RESSTEL, L. B.; GUIMARAES, F. S. The anxiolytic-like effects of cannabidiol injected into the bed nucleus of the stria terminalis are mediated by $5-\mathrm{HT} 1 \mathrm{~A}$ receptors. Psychopharmacology (Berl), v. 213, n. 2-3, p. 465-73, Feb 2011.

GRAY, C. L. et al. Dopamine in the nucleus accumbens modulates the memory of social defeat in Syrian hamsters (Mesocricetus auratus). Behav Brain Res, v. 286, p. 22-8, Jun 1 2015.

GUIMARAES, F. S. et al. Antianxiety effect of cannabidiol in the elevated plus-maze. Psychopharmacology (Berl), v. 100, n. 4, p. 558-9, 1990.

HAM, M. T.; DE JONG, Y. Absence of interaction between delta9-tetrahydrocannabinol (delta-THC) and cannabidiol (CBD) in aggression, muscle control and body temperature experiments in mice. Psychopharmacologia, v. 41, n. 2, p. 169-74, 1975.

HARING, M.; GUGGENHUBER, S.; LUTZ, B. Neuronal populations mediating the effects of endocannabinoids on stress and emotionality. Neuroscience, v. 204, p. 145-58, Mar 12012. 
HERKENHAM, M. et al. Cannabinoid receptor localization in brain. Proc Natl Acad Sci U S A, v. 87, n. 5, p. 1932-6, Mar 1990.

JOPPA, M. A.; ROWE, R. K.; MEISEL, R. L. Effects of serotonin 1A or 1B receptor agonists on social aggression in male and female Syrian hamsters. Pharmacol Biochem Behav, v. 58, n. 2, p. 349-53, Oct 1997.

JUNG, K. M. et al. Stimulation of endocannabinoid formation in brain slice cultures through activation of group I metabotropic glutamate receptors. Mol Pharmacol, v. 68, n. 5, p. 1196202, Nov 2005.

KIRBY, L. G. et al. Distinguishing characteristics of serotonin and non-serotonin-containing cells in the dorsal raphe nucleus: electrophysiological and immunohistochemical studies. Neuroscience, v. 116, n. 3, p. 669-83, 2003.

LINDGREN, T.; KANTAK, K. M. Effects of serotonin receptor agonists and antagonists of offensive aggression in mice. Aggress Behav, v. 13, p. 87-96, 1987.

LINNOILA, M. et al. Low cerebrospinal fluid 5-hydroxyindoleacetic acid concentration differentiates impulsive from nonimpulsive violent behavior. Life Sci, v. 33, n. 26, p. 2609-14, Dec 261983.

LISBOA, S. F. et al. Behavioral evaluation of male and female mice pups exposed to fluoxetine during pregnancy and lactation. Pharmacology, v. 80, n. 1, p. 49-56, 2007.

MACKIE, K. Distribution of cannabinoid receptors in the central and peripheral nervous system. Handb Exp Pharmacol, n. 168, p. 299-325, 2005.

MALICK, J. B. The pharmacology of isolation-induced aggressive behavior in mice. Curr Dev Psychopharmacol, v. 5, p. 1-27, 1979.

MARCO, E. M. et al. Endocannabinoid system and psychiatry: in search of a neurobiological basis for detrimental and potential therapeutic effects. Front Behav Neurosci, v. 5, p. 63, 2011.

MARINELLI, S. et al. Serotonergic and nonserotonergic dorsal raphe neurons are pharmacologically and electrophysiologically heterogeneous. J Neurophysiol, v. 92, n. 6, p. 3532-7, Dec 2004.

MARTIN, M. et al. Involvement of CB1 cannabinoid receptors in emotional behaviour. Psychopharmacology (Berl), v. 159, n. 4, p. 379-87, Feb 2002.

MATO, S. et al. CB1 knockout mice display impaired functionality of 5-HT1A and 5-HT2A/C receptors. J Neurochem, v. 103, n. 5, p. 2111-20, Dec 2007.

MCMILLEN, B.A. et al. N-alkyl-substituted aryl-piperazine drugs: relationship between affinity for serotonin receptor and inhibition of aggression. Drug Dev Res, v. 12, p. 53-62, 1988. 
MECHOULAM, R.; PARKER, L. A. The endocannabinoid system and the brain. Annu Rev Psychol, v. 64, p. 21-47, 2013.

MEHLMAN, P. T. et al. Low CSF 5-HIAA concentrations and severe aggression and impaired impulse control in nonhuman primates. Am J Psychiatry, v. 151, n. 10, p. 1485-91, Oct 1994.

MELIS, M. et al. Endocannabinoids mediate presynaptic inhibition of glutamatergic transmission in rat ventral tegmental area dopamine neurons through activation of CB1 receptors. J Neurosci, v. 24, n. 1, p. 53-62, Jan 72004.

MICZEK, K. A. et al. Alcohol and heightened aggression in individual mice. Alcohol Clin Exp Res, v. 22, n. 8, p. 1698-705, Nov 1998.

MICZEK, K. A. et al. Social and neural determinants of aggressive behavior: pharmacotherapeutic targets at serotonin, dopamine and gamma-aminobutyric acid systems. Psychopharmacology (Berl), v. 163, n. 3-4, p. 434-58, Oct 2002.

MICZEK, K. A.; HUSSAIN, S.; FACCIDOMO, S. Alcohol-heightened aggression in mice: attenuation by $5-\mathrm{HT} 1 \mathrm{~A}$ receptor agonists. Psychopharmacology (Berl), v. 139, n. 1-2, p. 160-8, Sep 1998.

MICZEK, K. A. et al. Aggressive behavioral phenotypes in mice. Behav Brain Res, v. 125, n. 1-2, p. 167-81, Nov 12001.

MICZEK, K. A. et al. Neurobiological mechanisms controlling aggression: preclinical developments for pharmacotherapeutic interventions. Neurosci Biobehav Rev, v. 18, n. 1, p. 97-110, Spring 1994.

MICZEK, K. A. et al. Aggression, anxiety and vocalizations in animals: GABAA and 5-HT anxiolytics. Psychopharmacology (Berl), v. 121, n. 1, p. 38-56, Sep 1995.

MORAND, C.; YOUNG, S. N.; ERVIN, F. R. Clinical response of aggressive schizophrenics to oral tryptophan. Biol Psychiatry, v. 18, n. 5, p. 575-8, May 1983.

MOREIRA, F. A. et al. Antiaversive effects of cannabinoids: is the periaqueductal gray involved? Neural Plast, v. 2009, p. 625469, 2009.

MOREIRA, F. A.; AGUIAR, D. C.; GUIMARAES, F. S. Anxiolytic-like effect of cannabidiol in the rat Vogel conflict test. Prog Neuropsychopharmacol Biol Psychiatry, v. 30, n. 8, p. 1466-71, Dec 302006.

MOREIRA, F. A.; AGUIAR, D. C.; GUIMARAES, F. S . Anxiolytic-like effect of cannabinoids injected into the rat dorsolateral periaqueductal gray. Neuropharmacology, v. 52, n. 3, p. 958-65, Mar 2007. 
MOS, J. et al. The effects of dorsal raphe administration of eltoprazine, TFMPP and 8-OHDPAT on resident intruder aggression in the rat. Eur $\mathbf{J}$ Pharmacol, v. 238, n. 2-3, p. 411-5, Jul 201993.

MOSIENKO, V. et al. Exaggerated aggression and decreased anxiety in mice deficient in brain serotonin. Transl Psychiatry, v. 2, p. e122, 2012.

MUEHLENKAMP, F.; LUCION, A.; VOGEL, W. H. Effects of selective serotonergic agonists on aggressive behavior in rats. Pharmacol Biochem Behav, v. 50, n. 4, p. 671-4, Apr 1995.

NELSON, M.; PINNA, G. S-norfluoxetine microinfused into the basolateral amygdala increases allopregnanolone levels and reduces aggression in socially isolated mice. Neuropharmacology, v. 60, n. 7-8, p. 1154-9, Jun 2011.

NELSON, R. J.; TRAINOR, B. C. Neural mechanisms of aggression. Nat Rev Neurosci, v. 8, n. 7, p. 536-46, Jul 2007.

O'BRIEN, C. Adicção a drogas. In: BRUNTON, L L; CHABNER, B A; KNOLLMANN, BC. As bases farmacológicas da terapêutica de Goodman \& Gilman. 12 ed. São Paulo: Artmed, 2012. p. 663-664.

OLIVIER, B. Serotonin and aggression. Ann N Y Acad Sci, v. 1036, p. 382-92, Dec 2004.

OLIVIER, B. Serotonin: a never-ending story. Eur J Pharmacol, v. 753, p. 2-18, Apr 15 2015.

OLIVIER, B. et al. Serotonin receptors and animal models of aggressive behavior. Pharmacopsychiatry, v. 28 Suppl 2, p. 80-90, Oct 1995.

PARENT, A.; DESCARRIES, L.; BEAUDET, A. Organization of ascending serotonin systems in the adult rat brain. A radioautographic study after intraventricular administration of [3H]5hydroxytryptamine. Neuroscience, v. 6, n. 2, p. 115-38, 1981.

PAZOS, M. R. et al. Mechanisms of cannabidiol neuroprotection in hypoxic-ischemic newborn pigs: role of $5 \mathrm{HT}(1 \mathrm{~A})$ and $\mathrm{CB} 2$ receptors. Neuropharmacology, v. 71, p. 282-91, Aug 2013.

PEDRAZZI, J. F. et al. Cannabidiol effects in the prepulse inhibition disruption induced by amphetamine. Psychopharmacology (Berl), v. 232, n. 16, p. 3057-65, Aug 2015.

PINNA, G. et al. In socially isolated mice, the reversal of brain allopregnanolone downregulation mediates the anti-aggressive action of fluoxetine. Proc Natl Acad Sci U S A, v. 100, n. 4, p. 2035-40, Feb 182003.

RANG, H.P., et al. Canabinoides. In: Rang, H P; DALE, M M; RITTER, J M; FLOWER, R J; HENDERSON, G. Rang \& Dale - Farmacologia. 7 ed. Rio de Janeiro: Elsevier, 2011. p. 221-227. 
RESSTEL, L. B. et al. Effects of cannabidiol and diazepam on behavioral and cardiovascular responses induced by contextual conditioned fear in rats. Behav Brain Res, v. 172, n. 2, p. 294-8, Sep 252006.

RESSTEL, L. B. et al. 5-HT1A receptors are involved in the cannabidiol-induced attenuation of behavioural and cardiovascular responses to acute restraint stress in rats. $\mathbf{B r} \mathbf{J}$ Pharmacol, v. 156, n. 1, p. 181-8, Jan 2009.

REY, A. A. et al. Biphasic effects of cannabinoids in anxiety responses: $C B 1$ and $G A B A(B)$ receptors in the balance of GABAergic and glutamatergic neurotransmission. Neuropsychopharmacology, v. 37, n. 12, p. 2624-34, Nov 2012.

RODRIGUEZ-ARIAS, M. et al. CB1 cannabinoid receptor-mediated aggressive behavior. Neuropharmacology, v. 75, p. 172-80, Dec 2013.

RUBINO, T. et al. Role in anxiety behavior of the endocannabinoid system in the prefrontal cortex. Cereb Cortex, v. 18, n. 6, p. 1292-301, Jun 2008.

RUSSO, E. B. et al. Agonistic properties of cannabidiol at 5-HT1a receptors. Neurochem Res, v. 30, n. 8, p. 1037-43, Aug 2005.

RYBERG, E. et al. The orphan receptor GPR55 is a novel cannabinoid receptor. $\mathbf{B r} \mathbf{J}$ Pharmacol, v. 152, n. 7, p. 1092-101, Dec 2007.

SAKAUE, M. et al. Involvement of benzodiazepine binding sites in an antiaggressive effect by $5-\mathrm{HT}(1 \mathrm{~A})$ receptor activation in isolated mice. Eur $\mathbf{J}$ Pharmacol, v. 432, n. 2-3, p. 163-6, Dec 72001.

SAKAUE, M. et al. Modulation by 5-hT2A receptors of aggressive behavior in isolated mice. Jpn J Pharmacol, v. 89, n. 1, p. 89-92, May 2002.

SANCHEZ, C. et al. The role of serotonergic mechanisms in inhibition of isolation-induced aggression in male mice. Psychopharmacology (Berl), v. 110, n. 1-2, p. 53-59, 1993.

SANCHEZ, C.; HYTTEL, J. Isolation-induced aggression in mice: effects of 5hydroxytryptamine uptake inhibitors and involvement of postsynaptic 5-HT1A receptors. Eur J Pharmacol, v. 264, n. 3, p. 241-7, Nov 31994.

SANDERS-BUSCH, E.; HAZELWOOD, L. 5-Hidroxitriptamina (serotonina) e dopamina. In: BRUNTON, L L; CHABNER, B A; KNOLLMANN, BC. As bases farmacológicas da terapêutica de Goodman \& Gilman. 12 ed. São Paulo: Artmed, 2012. p. 335-9.

SIJBESMA, $\mathrm{H}$. et al. Postsynaptic 5-HT1 receptors and offensive aggression in rats: a combined behavioural and autoradiographic study with eltoprazine. Pharmacol Biochem Behav, v. 38, n. 2, p. 447-58, Feb 1991. 
SOARES VDE, P. et al. Intra-dorsal periaqueductal gray administration of cannabidiol blocks panic-like response by activating 5-HT1A receptors. Behav Brain Res, v. 213, n. 2, p. 225-9, Dec 12010.

SPERRY, T. S.; THOMPSON, C. K.; WINGFIELD, J. C. Effects of acute treatment with 8OH-DPAT and fluoxetine on aggressive behaviour in male song sparrows (Melospiza melodia morphna). J Neuroendocrinol, v. 15, n. 2, p. 150-60, Feb 2003.

STEIN, D. J. et al. Aggression-reducing effects of F15599, a novel selective 5-HT1A receptor agonist, after microinjection into the ventral orbital prefrontal cortex, but not in infralimbic cortex in male mice. Psychopharmacology (Berl), v. 230, n. 3, p. 375-87, Dec 2013.

STEINBUSCH, H. W. Distribution of serotonin-immunoreactivity in the central nervous system of the rat-cell bodies and terminals. Neuroscience, v. 6, n. 4, p. 557-618, 1981.

TAKAHASHI, A. et al. Brain serotonin receptors and transporters: initiation vs. termination of escalated aggression. Psychopharmacology (Berl), v. 213, n. 2-3, p. 183-212, Feb 2011.

TEN EYCK, G. R. Serotonin modulates vocalizations and territorial behavior in an amphibian. Behav Brain Res, v. 193, n. 1, p. 144-7, Nov 32008.

THOMAS, A. et al. Cannabidiol displays unexpectedly high potency as an antagonist of CB1 and CB2 receptor agonists in vitro. Br J Pharmacol, v. 150, n. 5, p. 613-23, Mar 2007.

TOMPKINS, E.C.; CLEMENTO, A.J.; TAYLOR, D. P.; PERHACH, J.L. Jr. Inhibition of aggrerssive behavior in Rhesus monkeys by buspirone. Res Commun Psuchol Psych Behav, v. 5, p. 337-52, 1980.

TWARDOWSCHY, A. et al. The role of 5-HT1A receptors in the anti-aversive effects of cannabidiol on panic attack-like behaviors evoked in the presence of the wild snake Epicrates cenchria crassus (Reptilia, Boidae). J Psychopharmacol, v. 27, n. 12, p. 1149-59, Dec 2013.

VAN ERP, A. M.; MICZEK, K. A. Aggressive behavior, increased accumbal dopamine, and decreased cortical serotonin in rats. J Neurosci, v. 20, n. 24, p. 9320-5, Dec 152000.

VAN HONK, J. et al. Socially explosive minds: the triple imbalance hypothesis of reactive aggression. J Pers, v. 78, n. 1, p. 67-94, Feb 2010.

VAN REE, J. M.; NIESINK, R. J.; NIR, I. delta 1-Tetrahydrocannabinol but not cannabidiol reduces contact and aggressive behavior of rats tested in dyadic encounters. Psychopharmacology (Berl), v. 84, n. 4, p. 561-5, 1984.

VERGNES, M.; DEPAULIS, A.; BOEHRER, A. Parachlorophenylalanine-induced serotonin depletion increases offensive but not defensive aggression in male rats. Physiol Behav, v. 36, n. 4, p. 653-8, 1986. 
VIRKKUNEN, M. et al. CSF biochemistries, glucose metabolism, and diurnal activity rhythms in alcoholic, violent offenders, fire setters, and healthy volunteers. Arch Gen Psychiatry, v. 51, n. 1, p. 20-7, Jan 1994.

VIVEROS, M. P.; MARCO, E. M.; FILE, S. E. Endocannabinoid system and stress and anxiety responses. Pharmacol Biochem Behav, v. 81, n. 2, p. 331-42, Jun 2005.

WALZ, J.C. et al. Tryptophan diet reduces aggressive behavior in male mice. Psychol Neurosci, v. 6, 397-401, 2013.

WILSON, R. I.; NICOLL, R. A. Endocannabinoid signaling in the brain. Science, v. 296, n. 5568, p. 678-82, Apr 262002.

ZANELATI, T. V. et al. Antidepressant-like effects of cannabidiol in mice: possible involvement of 5-HT1A receptors. Br J Pharmacol, v. 159, n. 1, p. 122-8, Jan 2010.

ZUARDI, A. W. et al. Effects of ipsapirone and cannabidiol on human experimental anxiety. J Psychopharmacol, v. 7, n. 1 Suppl, p. 82-8, Jan 1993.

ZUARDI, A. W.; RODRIGUES, J. A.; CUNHA, J. M. Effects of cannabidiol in animal models predictive of antipsychotic activity. Psychopharmacology (Berl), v. 104, n. 2, p. 260-4, 1991. 